\section{OPEN ACCESS}

Edited by:

Louis Grillet,

Academia Sinica, Taiwan

Reviewed by:

Takashi Hirayama,

Okayama University, Japan

Jeeyon Jeong,

Amherst College, United States

Ya-Fen Lin,

National Taiwan University, Taiwan

*Correspondence: Lola Peñarrubia penarrub@uv.es

${ }^{\dagger}$ Present address: Amparo Andrés-Bordería Departamento de Fisiología, Facultad de Medicina, Universitat de València, Valencia, Spain

Specialty section:

This article was submitted to Plant Traffic and Transport,

a section of the journa

Frontiers in Plant Science

Received: 24 January 2020 Accepted: 06 July 2020

Published: 23 July 2020

Citation:

Perea-García A, Andrés-Bordería A, Vera-Sirera F, Pérez-Amador MA, Puig S and Peñarrubia L (2020)

Deregulated High Affinity Copper Transport Alters Iron Homeostasis in Arabidopsis.

Front. Plant Sci. 11:1106. doi: 10.3389/fpls.2020.01106

\title{
Deregulated High Affinity Copper Transport Alters Iron Homeostasis in Arabidopsis
}

\begin{abstract}
Ana Perea-García ${ }^{1}$, Amparo Andrés-Bordería ${ }^{2+}$, Francisco Vera-Sirera ${ }^{3}$, Miguel Angel Pérez-Amador ${ }^{3}$, Sergi Puig ${ }^{1}$ and Lola Peñarrubia ${ }^{2 *}$
\end{abstract}

${ }^{1}$ Departamento de Biotecnología, Instituto de Agroquímica y Tecnología de Alimentos (IATA), Consejo Superior de Investigaciones Científicas (CSIC), Paterna, Valencia, Spain, ${ }^{2}$ Departament de Bioquímica i Biologia Molecular and Estructura de Recerca Interdisciplinar en Biotecnologia i Biomedicina (ERI BIOTECMED), Universitat de València, Burjassot, Valencia, Spain, ${ }^{3}$ Instituto de Biología Molecular y Celular de Plantas (IBMCP), Consejo Superior de Investigaciones Científicas (CSIC) - Universidad Politécnica de Valencia (UPV), Valencia, Spain

The present work describes the effects on iron homeostasis when copper transport was deregulated in Arabidopsis thaliana by overexpressing high affinity copper transporters COPT1 and COPT3 (COPT ${ }^{O E}$ ). A genome-wide analysis conducted on COPT1 ${ }^{O E}$ plants, highlighted that iron homeostasis gene expression was affected under both copper deficiency and excess. Among the altered genes were those encoding the iron uptake machinery and their transcriptional regulators. Subsequently, COPT ${ }^{O E}$ seedlings contained less iron and were more sensitive than controls to iron deficiency. The deregulation of copper (I) uptake hindered the transcriptional activation of the subgroup Ib of basic helix-loop-helix ( $b H L H-l b)$ factors under copper deficiency. Oppositely, copper excess inhibited the expression of the master regulator FIT but activated $b H L H-I b$ expression in $C O P T^{O E}$ plants, in both cases leading to the lack of an adequate iron uptake response. As copper increased in the media, iron (III) was accumulated in roots, and the ratio iron (III)/iron (II) was increased in COPT ${ }^{O E}$ plants. Thus, iron (III) overloading in $C O P T^{O E}$ roots inhibited local iron deficiency responses, aimed to metal uptake from soil, leading to a general lower iron content in the COPT ${ }^{O E}$ seedlings. These results emphasized the importance of appropriate spatiotemporal copper uptake for iron homeostasis under non-optimal copper supply. The understanding of the role of copper uptake in iron metabolism could be applied for increasing crops resistance to iron deficiency.

Keywords: Arabidopsis thaliana, copper uptake, high affinity copper importer 1, iron homeostasis, metal interactions, metal mobilization

\section{INTRODUCTION}

Copper $(\mathrm{Cu})$ and iron $(\mathrm{Fe})$ are transition metals with redox properties that form coordination complexes with organic molecules, acting as essential cofactors in numerous proteins, including components of the respiratory and photosynthetic electron transport chains (Puig et al., 2007; Nouet et al., 2011; Yruela, 2013). However, these redox properties also make $\mathrm{Cu}$ and Fe potentially 
toxic since they facilitate the formation of reactive oxygen species (ROS). ROS produce damage at different levels, as they are able to react with proteins, DNA, and lipids in cell membranes, altering their function (Ravet and Pilon, 2013). Metal iondependent redox biology constitutes a fundamental theme of aerobic life. Nowadays, both multicopper oxidases (MCO), functioning as metallooxidases, and metalloreductases from the FERRIC REDUCTASE OXIDASE (FRO) family are necessary in redox cycling processes required for metal trafficking in eukaryotic cells (Kosman, 2018). Since evolved in an anaerobic environment, the proto-aerobe organisms developed metalloreductases to supply reduced metals $\mathrm{Fe}^{2+}$ and $\mathrm{Cu}^{+}$to transporters. Changes in the bioavailability of both metals throughout the evolution of the atmosphere led to a decrease and increase in the $\mathrm{Fe}$ and $\mathrm{Cu}$ bioavailability, respectively, allowing their substitution as cofactors in different proteins to perform similar functions (Crichton and Pierre, 2001). For instance, in Arabidopsis thaliana, Cu/Zinc ( $\mathrm{Zn}$ ) superoxide dismutase (SOD) is replaced by its Fe counterpart when $\mathrm{Cu}$ is scarce (Yamasaki et al., 2007). Metalloprotein substitution contributes to the increase of Fe content under $\mathrm{Cu}$ deficiency and vice versa (Waters et al., 2012).

Higher plants have developed sophisticated mechanisms to efficiently acquire and use micronutrients such as $\mathrm{Cu}$ and $\mathrm{Fe} . \mathrm{Cu}$ and specially $\mathrm{Fe}$ deficiencies cause losses in agriculture by decreasing the productivity and nutritional value of crops. The deficiency of $\mathrm{Fe}$ in agriculture is due to its low bioavailability, especially in alkaline soils (Marschner, 2012). From the two classically described pathways for $\mathrm{Fe}$ acquisition in plants, Arabidopsis uses strategy I that is based on the reduction of $\mathrm{Fe}^{3+}$ to $\mathrm{Fe}^{2+}$ by the reductase $\mathrm{FRO} 2$ present in the root plasma membrane (Robinson et al., 1999). The ZIP-type divalent cation transporter IRON-REGULATED TRANSPORTER 1 (IRT1) incorporates the $\mathrm{Fe}^{2+}$ into the root cell (Connolly et al., 2002; Varotto et al., 2002; Vert et al., 2002). In the chloroplast, Fe participates in the electron transport chain, chlorophyll biosynthesis, the assembly of Fe/S clusters, and the biosynthesis of heme groups, among other processes (Yruela, 2013). Mitochondria are also high Fe consumer organelles mainly for the electron transport chain and the assembly of Fe/S groups (Nouet et al., 2011). Therefore, due to the possibility of forming ROS, Fe is complexed by the ferritin protein (Reyt et al., 2015). The transcription factor FIT (bHLH29) (FER-like IRON DEFICIENCY INDUCED TRANSCRIPTION FACTOR) is a basic helix-loop-helix (bHLH) that binds to DNA in response of Fe deficiency (Colangelo and Guerinot, 2004). FIT interacts and forms heterodimers with the subgroup $\mathrm{Ib}$ of bHLH proteins (bHLH38, bHLH39, bHLH100 and bHLH101), which are required to properly respond to Fe deficiency (Wang et al., 2013). Among the genes activated by FIT are those encoding the reductase FRO2 and the $\mathrm{Fe}$ and $\mathrm{Cu}$ transporters IRT1 and COPT2, respectively (Colangelo and Guerinot, 2004). FIT activity is regulated at multiple levels by hormones, oxidative stress, and other signals, being considered as a hub modulating the Arabidopsis strategy I response to Fe deficiency (Kobayashi, 2019).
Other regulators of $\mathrm{Fe}$ uptake are the IRON MAN/FEUPTAKE-INDUCING PEPTIDE (IMA/FEP), a group of conserved plant peptides induced under Fe deficiency in vascular tissues (Grillet et al., 2018; Hirayama et al., 2018). Moreover, several phytohormones are involved in modulating Fe deficiency responses in plants. Ethylene, auxin, gibberellin, and salicylic acid function as positive factors of the Fe-deficiency responses, whereas cytokinin, brassinosteroid, abscisic acid, and jasmonic acid act as negative factors of Fe uptake (Kobayashi, 2019). The balance between cellular proliferation and differentiation in the Arabidopsis root has been attributed to the transcription factor UPBEAT1 (UPB1), which regulates this balance through ROS control (Tsukagoshi et al., 2010). Among the upstream regulators is ILR3 (bHLH105), from the subgroup IVc of bHLH transcription factors, which is induced under Fe deficiency and inhibits the expression of genes such as At-NEET, FER1, and FER3 (Tissot et al., 2019). ILR3 and bHLH115 interact with the E3 ubiquitin ligase BRUTUS (BTS), which ubiquitinates them for degradation (Selote et al., 2015). BTS is a protein that participate in Fe sensing, with highly conserved domains including 3 hemerythrin domains, and a protein-protein interaction domain denoted REALLY INTERESTING NEW GENE (RING) (Long et al., 2010; Kobayashi et al., 2013). BTS and its paralogs are negative regulators of $\mathrm{Fe}$ assimilatory responses (Hindt et al., 2017).

$\mathrm{Cu}$ is found in the form of $\mathrm{Cu}^{2+}$ in the soil, although under metal deficiency it is introduced in the root cells as $\mathrm{Cu}^{+}$by high affinity Ctr transporters, denoted COPT (COPPER TRANSPORTERS) in plants (Puig, 2014; Peñarrubia et al., 2015). Previous to $\mathrm{Cu}^{+}$uptake, reductases, from the FRO family participate in the reduction of $\mathrm{Cu}^{2+}$ (Bernal et al., 2012). The Ctr protein family is conserved in eukaryotes and mediates cellular $\mathrm{Cu}^{+}$acquisition (Nevitt et al., 2012). The recently solved X-ray structure of a Ctr member has confirmed that each monomer contains three transmembrane segments that assemble as homotrimers or heterotrimers and that $\mathrm{Cu}^{+}$is incorporated through a central pore (Ren et al., 2019). From the six genes identified in Arabidopsis that encode COPT transporters (Sancenón et al., 2003; Garcia-Molina et al., 2013), COPT1 and COPT3 are both induced by $\mathrm{Cu}$ deficiency and their encoded proteins are located into plasma membrane and at a compartment of the secretory pathway, respectively (AndrésColás et al., 2010; Andrés-Colás et al., 2018). The phenotypes of plants with altered levels of COPT1 and COPT3 correlate with their expression at the pollen grains and suggest a predominant role of COPT1, also expressed at the root tip, in the acquisition of Cu from the soil (Sancenón et al., 2004; Andrés-Colás et al., 2010; Andrés-Colás et al., 2018). Constitutive COPT1 and COPT3 overexpression (COPT ${ }^{O E}$ plants) lead to increased $\mathrm{Cu}$ uptake, oxidative stress, and phenotypes related to altered circadian rhythms (Andrés-Colás et al., 2010; Rodrigo-Moreno et al., 2013; Perea-García et al., 2016; Sanz et al., 2019). Furthermore, the Arabidopsis COPT1 transporter has been overexpressed in Oryza sativa plants, leading to increased Fe content in polished grains (Andrés-Bordería et al., 2017). These results underscore the effects of $\mathrm{Cu}$ status on Fe traffic and mobilization. Moreover, 
COPT2 is the Arabidopsis transporter with the highest expression along the root, and plants defective in COPT2 are more resistant to double $\mathrm{Cu}$ and Fe deficiency (Perea-García et al., 2013). In fact, the COPT2 promoter contains E-Box elements to which FIT binds (Colangelo and Guerinot, 2004). On the other hand, $\mathrm{Cu}$ deficiency involves the regulation of many metabolic processes to allocate the little $\mathrm{Cu}$ present to essential proteins. The $\mathrm{Zn}$ finger transcription factor SQUAMOSAPROMOTER BINDING-LIKE PROTEIN 7 (SPL7) binds to GTAC consensus sequences present in the promoters of various genes that are expressed under $\mathrm{Cu}$ deficiency, such as COPT2 (Yamasaki et al., 2009; Bernal et al., 2012). The presence of both cis regulatory elements justifies COPT2 induction in the double deficiency of $\mathrm{Cu}$ and Fe (Perea-García et al., 2013).

The importance of the regulation of metal homeostasis, at both the cellular and the systemic levels, and its implications in agriculture and human health is evident. However, the molecular mechanisms underlying the interaction between both metals remain poorly understood (Gulec and Collins, 2014). As far as metal homeostasis networks for a specific metal are becoming well understood, the crosstalk between different metals is starting to emerge as a possibility to improve global metal nutritional levels for optimal organismal performing.

\section{MATERIALS AND METHODS}

\section{Plant Growth Conditions and Treatments}

Seeds of A. thaliana, ecotype Columbia-O (Col-0) and of the transgenic lines $C O P T 1^{O E}$ and $C O P T 3^{O E}$ were surface-sterilized and stratified for 2 days at $4^{\circ} \mathrm{C}$ and were germinated in $1 / 2 \mathrm{MS}$ medium (Sigma) plates including $1 \%$ sucrose (Murashige and Skoog, 1962) (1/2 MS) or supplemented with $10 \mu \mathrm{M} \mathrm{CuSO}_{4}(1 / 2$ $\mathrm{MS}+10 \mathrm{Cu}$ ) for the microarray analysis. Seedlings were grown as previously described (Andrés-Colás et al., 2010) for 7 days with a $12 \mathrm{~h}$ neutral photoperiod $\left(65 \mu \mathrm{mol} \mathrm{m} \mathrm{m}^{-2}\right.$ of cool-white fluorescent light) at $23^{\circ} \mathrm{C} / 16^{\circ} \mathrm{C}$ temperature cycle.

In order to obtain $1 / 2$ MS medium with the indicated concentrations of either $\mathrm{Cu}$ or $\mathrm{Fe}$, the solution was prepared by adding macronutrients (Sigma) and micronutrients consisted in a mix of $50 \mu \mathrm{M} \mathrm{H}_{3} \mathrm{BO}_{3}, 36.6 \mu \mathrm{M} \mathrm{MnSO}_{4} \mathrm{H}_{2} \mathrm{O}, 15 \mu \mathrm{M} \mathrm{ZnSO}$ $7 \mathrm{H}_{2} \mathrm{O}, 0.57 \mu \mathrm{M} \mathrm{NaMoO}{ }_{4} 2 \mathrm{H}_{2} \mathrm{O}, 0.25 \mathrm{mM} \mathrm{KI}$, and $0.05 \mu \mathrm{M}$ $\mathrm{CoCl}_{2} 6 \mathrm{H}_{2} \mathrm{O}$. Finally, $0.05 \%$ MES, $1 \%$ sucrose, and $0.8 \%$ phytoagar was added, and the $\mathrm{pH}$ was adjusted to 5.7-5.8 with diluted $\mathrm{KOH}$. The $\mathrm{Cu}$ concentration in the $\mathrm{Cu}$ deficiency $(0 \mu \mathrm{M}$ $\mathrm{CuSO}_{4}$ ) media including commercial phytoagar (Duchefa Biochemie) measured by ICP-MS is $<0.008 \mu \mathrm{M} \mathrm{Cu}$. To study the effects that the different $\mathrm{Cu}$ and $\mathrm{Fe}$ content have in plants, 50 $\mu \mathrm{M} \mathrm{Fe}$-citrate and $1 \mu \mathrm{M} \mathrm{CuSO}_{4} 5 \mathrm{H}_{2} \mathrm{O}$ were added to the medium for $\mathrm{Cu}$ and $\mathrm{Fe}$ sufficiency conditions. Moreover, seedlings were grown in $\mathrm{Cu}$ deficiency $\left.(0 \mu \mathrm{M} \mathrm{CuSO})_{4}\right)$ and $\mathrm{Cu}$ excess $(10 \mu \mathrm{M}$ $\left.\mathrm{CuSO}_{4}\right)$. On the other hand, Fe-sufficient and slight or severe Fe deficiency medium was supplemented with 50, 10 and $0 \mu \mathrm{M} \mathrm{Fe-}$ citrate, respectively. Other metal concentrations and treatments were used for specific experiments as indicated in the Supplementary Figure Legends.

The chlorophyll content in seedlings and leaves was determined by the trichlorometric method (Parsons and Strickland, 1965). Root length was measured using the Image J 1.42q software (http://rsb.info.nih.gov./ij). Values represent the arithmetic mean \pm standard deviation $(\mathrm{SD})$ of three biological replicates $(n=3)$.

For the determination of ferroreductase activity, three seedlings of 7-day-old were collected and weighed. Next, a 1:1 mixture made with $300 \mu \mathrm{M}$ bathophenantroline disulfonate (BPDS, Sigma) and $100 \mu \mathrm{M}$ Fe III-EDTA was added to the seedlings and incubated at $30^{\circ} \mathrm{C}$ with stirring $225 \mathrm{rpm}$ in the dark. After $30 \mathrm{~min}$, the solution was collected and absorbance $A_{535}$ was measured in a spectrophotometer (Grillet et al., 2014). Values represent the arithmetic mean \pm standard deviation (SD) of three biological replicates $(n=3)$.

For root $\mathrm{Fe}^{3+}$ detection by Perl's staining, four to five seedlings of 11-day-old were vacuum infiltrated with equal volumes of $4 \%(\mathrm{v} / \mathrm{v}) \mathrm{HCl}$ and $4 \%(\mathrm{w} / \mathrm{v}) \mathrm{K}$ - ferrocyanide (Perl's stain solution for $15 \mathrm{~min}$ ) and incubated at room temperature for $30 \mathrm{~min}$ (Stacey et al., 2008). One representative photograph is shown in the figure. This method is based on the $\mathrm{Fe}^{3+}$ dependent conversion of ferrocyanide into insoluble crystals of Prussian blue under acidic conditions. Localization of $\mathrm{Fe}^{3+}$ was observed and analyzed with a (Olympus CX41) microscope equipped with (Leyca MC170HD) camera and (LAS V4.10) software.

\section{Microarrays and Bioinformatics}

Seven-day-old seedlings of the WT and the COPT1 ${ }^{O E}$ line were grown in the $12 \mathrm{~h}$ neutral photoperiod and three biological replicates were obtained for the $(1 / 2 \mathrm{MS})$ treatment and four biological replicates were used as $10 \mu \mathrm{M} \mathrm{CuSO}_{4},(1 / 2 \mathrm{MS}+10 \mathrm{Cu})$ samples. Total RNA was isolated using the RNeasy Plant Mini Kit (Qiagen) and aRNA was amplified using the MessageAmp ${ }^{\text {TM }}$ II aRNA Amplification kit (Ambion). Long oligonucleotide microarrays were provided by Dr. David Galbraith (University of Arizona, http://www.ag.arizona.edu/microarray/). The hybridization and analysis were performed as described elsewhere (Bueso et al., 2007). The expression values $\left(\log _{2}\right)$ were obtained using the GenePix Pro 6.0 microarray-analysis software (Molecular Devices, Sunnyvale CA) and normalized with the GenePix Pro 6.0 and Acuity 4.0 software (Molecular Devices, Sunnyvale CA). Differential genes were identified with significance analysis of microarray (SAM) (Tusher et al., 2001) with false discovery rate (FDR) of $<6 \%$ and 2 -fold change $\left(\log _{2} \leq|1|\right)$. Biological processes were identified with the Gene Ontology (GO) annotation (Ashburner et al., 2000), performed by the GeneCodis2.0 (http://genecodis.dacya.ucm.es/) (Carmona-Saez et al., 2007; Nogales-Cadenas et al., 2009) program (Table 1). The total differentially regulated genes are shown as Supplementary material (Supplementary Tables SI and SII). The microarray raw data were deposited in the NCBI's Gene Expression Omnibus (Edgar, 2002) and are accessible through GEO Series accession number GSE143857. 
TABLE 1 | Differentially expressed iron- and tetrapyrrole-related genes in COPT1 ${ }^{O E}$ vs. WT seedlings in low and high Cu.

\begin{tabular}{|c|c|c|c|c|}
\hline \multirow[t]{2}{*}{ Gene Name } & \multirow[t]{2}{*}{ ID Gen } & \multirow[t]{2}{*}{ Description } & \multicolumn{2}{|c|}{ Value } \\
\hline & & & MS & $\mathrm{Cu}$ \\
\hline \multicolumn{5}{|c|}{ Fe homeostasis } \\
\hline IRT1 & AT4G19690 & Iron-regulated transporter 1 & -1.74 & -1.77 \\
\hline FRO2 & AT1G01580 & Ferric reduction oxidase 2 & - & -1.30 \\
\hline FRO3 & AT1G23020 & Ferric reduction oxidase 3 & 0.01 & 1.24 \\
\hline СОРT2 & AT3G46900 & Copper transporter 2 & -0.92 & -0.05 \\
\hline CYP82C4 & AT4G31940 & Cytochrome P450 & - & -2.59 \\
\hline FER1 & AT5G01600 & Ferritin 1 & -0.15 & -2.17 \\
\hline FER3 & AT3G56090 & Ferritin 3 & $-0,72$ & -0.71 \\
\hline At-NEET & AT5G51720 & Fe metabolism & -0.51 & -2.30 \\
\hline NAS4 & AT1G56430 & Nicotianamine syntase 4 & -1.51 & 0.64 \\
\hline OPT3 & AT4G16370 & Oligopeptide transporter 3 & -1.14 & 0.79 \\
\hline \multicolumn{5}{|l|}{ Fe regulators } \\
\hline FIT/bHLH29 & AT2G28160 & BHLH 29 & - & -0.39 \\
\hline bHLH039 & AT3G56980 & Basic helix-loop-helix protein 39 & -0.15 & 2.52 \\
\hline$b H L H 101$ & AT5G04150 & Basic helix-loop-helix protein 101 & 0.87 & 2.15 \\
\hline bHLH1OO & AT2G41240 & Basic helix-loop-helix protein 100 & 0.22 & 2,94 \\
\hline bHLH115 & AT1G51070 & Basic helix-loop-helix protein 115 & -1.14 & -0.05 \\
\hline UPB1 & AT2G47270 & Basic helix-loop-helix UPBEAT1 & 1.79 & -0.06 \\
\hline BTS & AT3G18290 & BRUTUS RING-ubiquitin ligase & -0.26 & 1.36 \\
\hline FEP2/IMA2 & AT1G47395 & Fe-Uptake-Inducing peptide2 & 0.29 & 3.32 \\
\hline FEP3/IMA1 & AT1G47400 & Fe-Uptake-Inducing peptide3 & 0.42 & 2.47 \\
\hline \multicolumn{5}{|c|}{ Tetrapyrrole retrograde signaling } \\
\hline CA1 & AT3G01500 & & -0.32 & -1.06 \\
\hline LHCB1.1 & AT1G29920 & & 0.34 & -0.97 \\
\hline LHCB1.4 & AT2G34430 & & - & -1.10 \\
\hline LHCB2.3 & AT3G27690 & & - & -1.80 \\
\hline LHCB4.1 & AT5G01530 & & - & -1.30 \\
\hline LHCB4.3 & AT2G40100 & & - & -1.34 \\
\hline LHCB5 & AT4G10340 & & -1.12 & -0.73 \\
\hline \multicolumn{5}{|l|}{ Components } \\
\hline HEMA1 & AT1G58290 & glutamyl-tRNA reductase 1, chloroplast & -2.13 & -1.46 \\
\hline GUN4 & AT3G59400 & genome uncoupled 4 & -1.00 & -1.36 \\
\hline $\mathrm{CHL27}$ & AT3G56940 & Copper response defect 1 & -0.10 & -0.76 \\
\hline SIG1 & AT1G64860 & Chloroplast sigma factor 1 & -1.70 & -1.16 \\
\hline
\end{tabular}

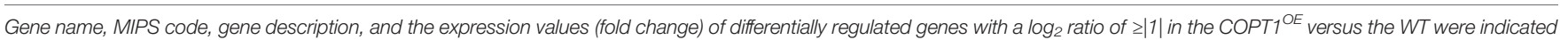
under $-\mathrm{Cu}(\mathrm{MS})$ and $+10 \mu \mathrm{M} \mathrm{Cu}(\mathrm{Cu})$. In bold are the genes that passed the statistical analysis.

\section{Gene Expression by Real-Time Quantitative PCR}

Total Arabidopsis RNA was isolated using the RNeasy Plant Mini Kit (Qiagen), was quantified by UV spectrophotometry and its integrity was visually assessed on ethidium bromide-stained agarose gels. After treatment with Dnase I Amp Grade (Invitrogen), cDNA was generated by retro-transcriptase SSII (Invitrogen) as previously described (Andrés-Colás et al., 2006). Real-time quantitative PCR (RT-qPCR) was carried out with SYBRGreen qPCR Super-Mix-UDG with ROX (Invitrogen) with the specific primers detailed in Table SVI in a CFX96 Touch $^{\mathrm{TM}}$ Real Time PCR Detection System (BioRad), with one cycle of $95^{\circ} \mathrm{C}$ for $2 \mathrm{~min}$ and 40 cycles consisting in $95^{\circ} \mathrm{C}$ for $30 \mathrm{~s}$ and $60^{\circ} \mathrm{C}$ for $30 \mathrm{~s}$. Expression values were normalized to $U B Q 10$ and to the WT in deficiency conditions using the $2^{-\Delta \Delta C t}$ method. Values represent the arithmetic mean \pm standard deviation $(\mathrm{SD})$ of three biological replicates $(n=3)$.

\section{Oxygen Consumption Determination}

To study $\mathrm{O}_{2}$ consumption, 14-16 roots of 10-day-old seedlings, grown in different conditions, were used. The roots were cut with a scalpel and resuspended in $1.5 \mathrm{ml}$ of $1 / 2 \mathrm{MS}$ liquid medium, as it is described above but without sucrose. The roots were transferred to an airtight chamber and the measurement of $\mathrm{O}_{2}$ consumption for a minimum of $5 \mathrm{~min}$ was performed using a Clark type electrode (Oxyview system). The rate of decrease of $\mathrm{O}_{2}$, referenced to fresh weight (F.W.) of the roots $\left(\mathrm{nmol} \mathrm{O}_{2} /\right.$ $\mathrm{OD}_{600} \times$ F.W.) was taken as an index of respiratory capacity. Values represent the arithmetic mean \pm standard deviation (SD) of three biological replicates $(n=3)$.

\section{Metal and Hormone Determinations}

$\mathrm{Cu}$ and Fe contents were determined by ICP-MS as described previously (Andrés-Colás et al., 2006; Carrió-Seguí et al., 2015) at the Servei Central de Suport a la Investigació Experimental (SCSIE) of the Universitat de València.

For the determination of the content of ABA, indol-3-acetic acid (IAA), and JA, 8-day-old seedlings were lyophilized, processed and analyzed by UHPLC (ultra-high-pressure liquid chromatography) Q-Exactive (ThermoFisher Scientific) as described previously (da Silva et al., 2017) in the plant hormone quantification service of the Institute of Molecular 
and Cellular Plant Biology (IBMCP, Valencia). Values represent the arithmetic mean \pm standard deviation (SD) of three biological replicates $(n=3)$.

\section{Statistical Analysis}

The statistical analysis of the relative gene expression was performed by the pair wise fixed reallocation randomization test ( $p$-value $<0.05$ ) (Pfaffl, 2002). For the remaining parameters, the analysis was carried out using one or two-way ANOVA with the means compared by the Duncan test or a Kruskal-Wallis ( $p$ value $<0.05)$ test for a non-parametric measurements using the InfoStat software, version 2010 (http://www.infostat.com.ar) (Di Rienzo et al., 2011).

\section{RESULTS}

\section{A Genome-Wide Expression Analysis Highlights That Iron Homeostasis Is Affected in COPT1 ${ }^{\text {OE }}$ Arabidopsis Plants}

To identify at a molecular level the global effects caused by the deregulation of $\mathrm{Cu}$ homeostasis in Arabidopsis, we performed a comparative transcriptomic analysis of 7-day-old wild-type (WT) and a previously generated COPT1 overexpressing $\left(C O P T 1^{O E}\right)$ line (Andrés-Colás et al., 2010), grown under $\mathrm{Cu}$ deficiency $(1 / 2 \mathrm{MS})$ and mild $\mathrm{Cu}$ excess $(1 / 2 \mathrm{MS}+10 \mathrm{Cu})$ conditions. The induction of COPT1 expression under $\mathrm{Cu}$ deficiency in the WT was corroborated by RT-qPCR, as well as its overexpression in $C O P T 1^{O E}$ seedlings, both under deficiency and excess $\mathrm{Cu}$ conditions, in the samples that were used in the hybridizations of the DNA microarrays (data not shown). From the global analysis of gene expression, a total of 583 differentially expressed genes were identified with a $\log _{2}$ ratio of $\geq|1|$ in the $C O P T 1^{O E}$ versus WT (Supplementary Figure $\mathbf{S 1}$ and Tables SI and SII). These were distributed in a total of 482 induced (ratio $\geq 1$ ) and of 101 repressed genes (ratio $\geq-1$ ) in $C O P T 1^{O E}$ seedlings for the two growth conditions tested (Supplementary Figure S1 and Supplementary Tables SI and SII).

The number of genes induced was greater than that of genes repressed in the two conditions. On the other hand, the mild $\mathrm{Cu}$ excess condition showed the greatest number of genes with differential expression compared to $\mathrm{Cu}$ deficiency, with 393 genes (312 induced and 81 repressed) compared to 160 genes (142 induced and 18 repressed), respectively. The analysis of the gene ontology $(\mathrm{GO})$ of differentially regulated genes between WT and $C O P T 1^{O E}$ seedlings indicated that several the Biological Processes categories were overrepresented, including those linked to photosynthesis, photomorphogenesis, transport of metals such as $\mathrm{Fe}, \mathrm{Zn}$, manganese, cadmium, and phosphate, oxidative stress and responses to abscisic acid (ABA) and cold stress (Supplementary Table SIII). On the other hand, the Molecular Function of genes differentially regulated in $C O P T 1^{O E}$ included the chlorophyll and tetrapyrrole binding (Supplementary Table SIV). GO analysis also revealed that the chloroplast was the subcellular compartment most affected by the changes observed in $C O P T 1^{O E}$, as $39 \%$ of the significantly enriched GO categories of Cellular Compartment are related to chloroplast (chloroplast, chloroplast envelope, thylakoid membrane, chloroplast membrane, stroma, photosystems I and II, and light-harvesting complex) (Supplementary Table SV). The Fe-related genes studied in this work, which expression was affected in $C O P T 1^{O E}$ plants, are summarized in Table $\mathbf{1 .}$

\section{Fe Assimilation in the COPT ${ }^{O E}$ Seedlings}

One of the most relevant result of the transcriptomic analysis in $C O P T 1^{O E}$ is the altered expression of Fe-related genes (Table 1), such as IRT1 and FRO2, involved in the strategy I of Fe uptake (Table 1). Expression of the Fe transporter IRT1 was reduced in $C O P T 1^{O E}$ seedling in both $\mathrm{Cu}$ deficiency $(1 / 2 \mathrm{MS})$ or excess $(1 / 2$ $\mathrm{MS}+10 \mathrm{Cu}$ ). In contrast, the genes encoding FRO reductases showed a different behavior; expression of $F R O 2$ was induced but that for $F R O 3$ was repressed in $C O P T 1^{O E}$ seedlings only in $\mathrm{Cu}$ excess. In order to further assess the effects of $\mathrm{Cu}$ on their expression, seedlings were grown on hand-made $1 / 2 \mathrm{MS}$ medium with three different $\mathrm{CuSO}_{4}$ concentrations, including $\mathrm{Cu}$ deficiency $\left(0 \mu \mathrm{M} \mathrm{CuSO}_{4}\right)$, sufficiency $\left(1 \mu \mathrm{M} \mathrm{CuSO}_{4}\right)$, and mild $\mathrm{Cu}$ excess $(10 \mu \mathrm{M} \mathrm{CuSO}$ ). Furthermore, in addition to $C O P T 1^{O E}$, plants overexpressing the COPT3 transporter $\left(C O P T 3^{O E}\right)$ (Andrés-Colás et al., 2010) were also included to further assess the effect of deregulated $\mathrm{Cu}^{+}$entrance (Figure 1). IRT1 expression slightly decreased in the WT seedlings as $\mathrm{Cu}$ increased in the medium, being significantly lower under $\mathrm{Cu}$ sufficiency and excess compared to deficiency conditions (Figure 1A). Similar to the global transcriptomic analysis, IRT1 expression in $C O P T^{O E}\left(C O P T 1^{O E}\right.$ and $C O P T 3^{O E}$ lines) was lower than in WT under both $\mathrm{Cu}$ deficiency and excess. Since genes encoding reductases FRO2 and FRO3 displayed distinct regulation in $C O P T 1^{O E}$ seedlings (Table 1), total ferroreductase activity was measured in the roots of 7-day-old $C O P T^{O E}$ seedlings (Figure 1B). No changes in ferroreductase activity were observed under $\mathrm{Cu}$ deficiency and sufficiency. However, a slightly lower ferroreductase activity was observed under $\mathrm{Cu}$ excess in the $C O P T 1^{O E}$ plants compared to the WT (Figure 1B).

$C O P T 1^{O E}$ and $C O P T 3^{O E}$ seedlings were previously shown to incorporate more $\mathrm{Cu}$, both under metal deficiency and excess in the growth medium (Andrés-Colás et al., 2010). Now, the Fe content was determined by ICP-MS in both shoots and roots from 7-day-old WT and $C O P T^{O E}$ seedlings grown under the different $\mathrm{Cu}$ conditions (Figures 1C, D). We observed that $C O P T^{O E}$ seedlings had slightly lower endogenous $\mathrm{Fe}$ concentration than the WT both in shoots and roots but only significant under $\mathrm{Cu}$ sufficiency and excess. This decrease was more evident in the roots of the COPT3 ${ }^{O E}$ seedlings (Figure 1D), which is consistent with their exacerbated reduction in IRT1 expression (Figure 1A).

To corroborate the expression changes of other Fe-related genes involved in $\mathrm{Fe}$ storage and metabolism in $C O P T 1^{O E}$ seedlings, we further investigated the expression of genes included in these processes, such as FER1, FER3, and At-NEET (Table 1 and Figure 2). Previous data have shown that the expression of FER1 is higher among the four genes (FER1, FER2, FER3 and FER4) that encode ferritins (Petit et al., 2001). FER1 and FER3 expression was down-regulated under $\mathrm{Cu}$ excess 
A

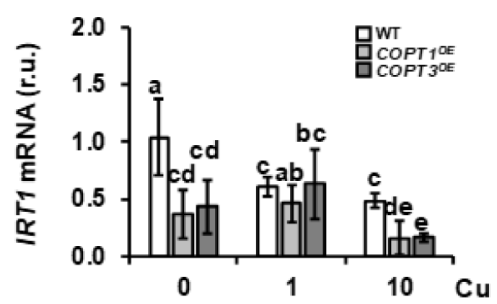

B

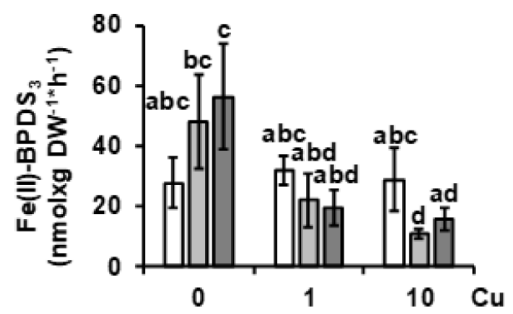

C
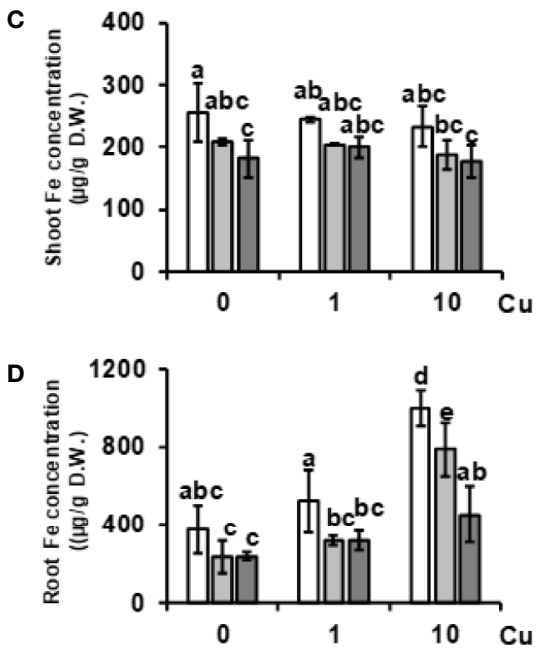

FIGURE 1 | Expression of strategy I components of Fe uptake in COPTOE seedlings. (A) Relative expression of IRT1 gene in 7-day-old WT (white bars), COPT1 ${ }^{O E}$ (light grey bars), and COPT3 ${ }^{O E}$ (dark grey bars) seedlings grown under $\mathrm{Cu}$ deficiency $\left(0 \mu \mathrm{M} \mathrm{CuSO}_{4}\right)$, sufficiency $\left(1 \mu \mathrm{M} \mathrm{CuSO}_{4}\right)$ or Cu excess (10 $\mu \mathrm{M} \mathrm{CuSO}_{4}$ ) was determined by RT-qPCR. Gene expression is represented as relative expression levels (r.u.) in relation to the WT under control conditions. UBQ10 was used as housekeeping gene. Bars correspond to arithmetic means $\left(2^{-\Delta \Delta C t}\right) \pm S D$ of biological replicates $(n=3)$. (B) Ferroreductase activity in 7 -dayold WT and COPT ${ }^{O E}$ seedlings grown in the same conditions as in (A) measured at $A_{535} \mathrm{~nm}$. Bars correspond to arithmetic means \pm SD of biological replicates $(n=3)(C)$ Shoot and (D) root Fe concentration in 7-day-old WT, COPT1 ${ }^{O E}$ and COPT3 ${ }^{O E}$ seedlings grown on $\mathrm{CuSO}_{4}$ media specified in (A) and determined as $\mu \mathrm{g} / \mathrm{g}$ of dry weight (D.W.). Bars correspond to arithmetic means \pm SD of biological replicates $(n=3)$. Samples with a letter in common are not significantly different ( $p$-value <0.05). D.W., dry weight.

compared to $\mathrm{Cu}$ deficiency in WT and this decrease was more exacerbated in $C O P T^{O E}$ seedlings (Table $\mathbf{1}$ and Figures $2 \mathbf{A}, \mathbf{B}$ ). This pattern is also in agreement with the lower Fe content in the $C O P T^{O E}$ under $\mathrm{Cu}$ excess (Figure 1C). At-NEET encodes a $\mathrm{Fe} / \mathrm{S}$ protein involved, among other processes, in the Fe metabolism and ROS homeostasis (Nechushtai et al., 2012; Mittler et al., 2019). At-NEET expression was induced under $\mathrm{Cu}$ deficiency in
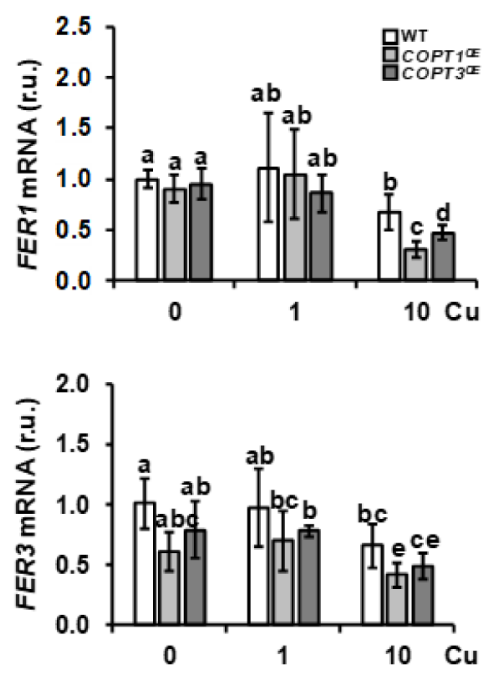

C

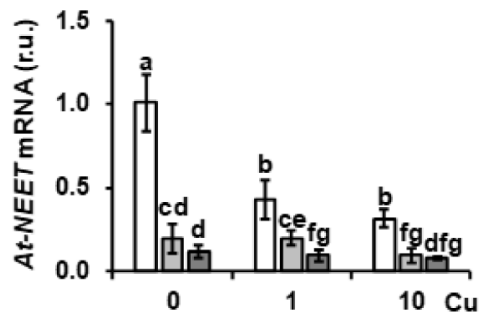

FIGURE 2 | Expression of Fe metabolism genes in COPT ${ }^{O E}$ seedlings. Relative expression of FER1 (A), FER3 (B), and At-NEET (C) genes in WT (white bars), $C O P T 1^{O E}$ (light grey bars), and $C O P{ }^{O E}$ (dark grey bars) seedlings grown under Cu deficiency $\left(0 \mu \mathrm{M} \mathrm{CuSO}_{4}\right)$, sufficiency $(1 \mu \mathrm{M}$ $\left.\mathrm{CuSO}_{4}\right)$ or $\mathrm{Cu}$ excess $\left(10 \mu \mathrm{M} \mathrm{CuSO}_{4}\right)$ was determined by RT-qPCR. Gene expression is represented as relative expression levels (r.u.) in relation to the WT under control conditions. UBQ10 was used as housekeeping gene. Bars correspond to arithmetic means $\left(2^{-\Delta \Delta C t}\right) \pm S D$ of biological replicates $(n=3)$. Samples with a letter in common are not significantly different ( $p$-value $<0.05)$.

the WT and reduced in the COPT ${ }^{O E}$ seedlings under all the $\mathrm{Cu}$ conditions studied (Table 1 and Figure 2C). The expression of FER1, FER3, and At-NEET was also analyzed under different $\mathrm{Cu}$ and Fe contents in WT seedlings (Supplementary Figure S2). Whereas all of them were induced under $\mathrm{Cu}$ deficiency compared to control conditions, only FER1 expression was repressed under Fe deficiency. FER3 and At-NEET were not regulated by Fe levels (Supplementary Figure S2). Altogether, these results indicate that the deregulated $\mathrm{Cu}^{+}$entrance in $C O P T^{O E}$ prevents the induction of genes involved in Fe uptake, leading ultimately to a reduced endogenous Fe content, and suggesting that overexpression of COPT may alter the local response to Fe deficiency in roots.

\section{Expression of Regulators of $\mathrm{Fe}$ Homeostasis in the COPT ${ }^{O E}$ Seedlings}

Certain Fe deficiency responses are under the control of the $\mathrm{Cu}$ responsive SPL7 transcription factor (Kastoori Ramamurthy 
et al., 2018). To determine whether the inhibition of IRT1 expression observed in $C O P T^{O E}$ could be a SPL7-mediated response, we checked the expression in $C O P T^{O E}$ seedlings of SPL7 and SPL7-regulated markers of $\mathrm{Cu}$ deficiency responses, such as COPT2 and FSD1 (Supplementary Figure S3), the latter encoding FeSOD (Yamasaki et al., 2009). SPL7 expression remained mostly unaffected in $C O P T^{O E}$. Whereas $C O P T 2$ expression was down-regulated in $C O P T^{O E}$ seedlings, FSD1 expression was not affected under $\mathrm{Cu}$ deficiency (Supplementary Figures S3B, C). Furthermore, other SPL7 targets were not differentially expressed in the COPT1 ${ }^{O E}$ seedlings under $\mathrm{Cu}$ deficiency (Tables SI and SII), indicating that the SPL7 factor was properly functioning in COPT ${ }^{O E}$ seedlings and it was not differentially affecting $\mathrm{Cu}$ deficiency responses in these plants. On the other hand, the expression of CSD2, encoding the chloroplastic $\mathrm{Cu} / \mathrm{Zn}$ SOD CSD2, was reduced in $C O P T^{O E}$ seedlings under $\mathrm{Cu}$ sufficiency and excess (Supplementary Figure S3D).
To further address the role of $\mathrm{Cu}$ in the lack of Fe-deficiency response, we analyzed the expression of Fe-related bHLH transcription factors and other regulators (Table 1 and Figure 3). A slight increase and a lower expression were observed for FIT under $\mathrm{Cu}$ deficiency and excess, respectively, in $C O P T 1^{O E}$ seedlings compared to the WT (Figure 3A). Consistent with FIT inhibition under $\mathrm{Cu}$ excess, the expression of two of its targets, IRT1 and COPT2, was slightly repressed in COPT ${ }^{O E}$ seedlings (Figure 1A and Supplementary Figure S3B), which suggests that high $\mathrm{Cu}$ in these plants represses the activity of this master Fe uptake regulator. The expression of the subgroup Ib of Ferelated bHLH (bHLH38, bHLH39, bHLH100 and bHLH101) transcription factors was also analyzed (Figures 3B, C, Supplementary Figures S4A, B). We observed that, in the WT plants, expression of $b H L H-I b$ factors was in general greater as $\mathrm{Cu}$ increased in the growth medium. Remarkably, its expression was highly increased in $C O P T 1^{O E}$ seedlings under $\mathrm{Cu}$ excess conditions (Figure 3 and Supplementary Figure S4). Therefore,
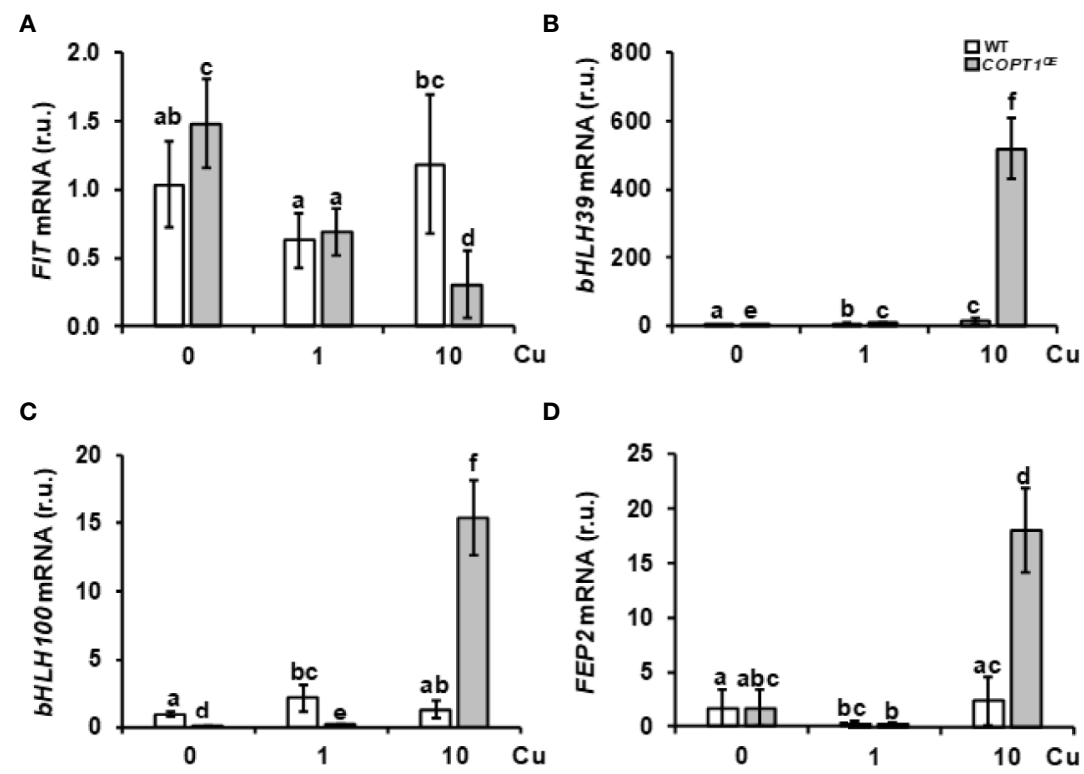

D
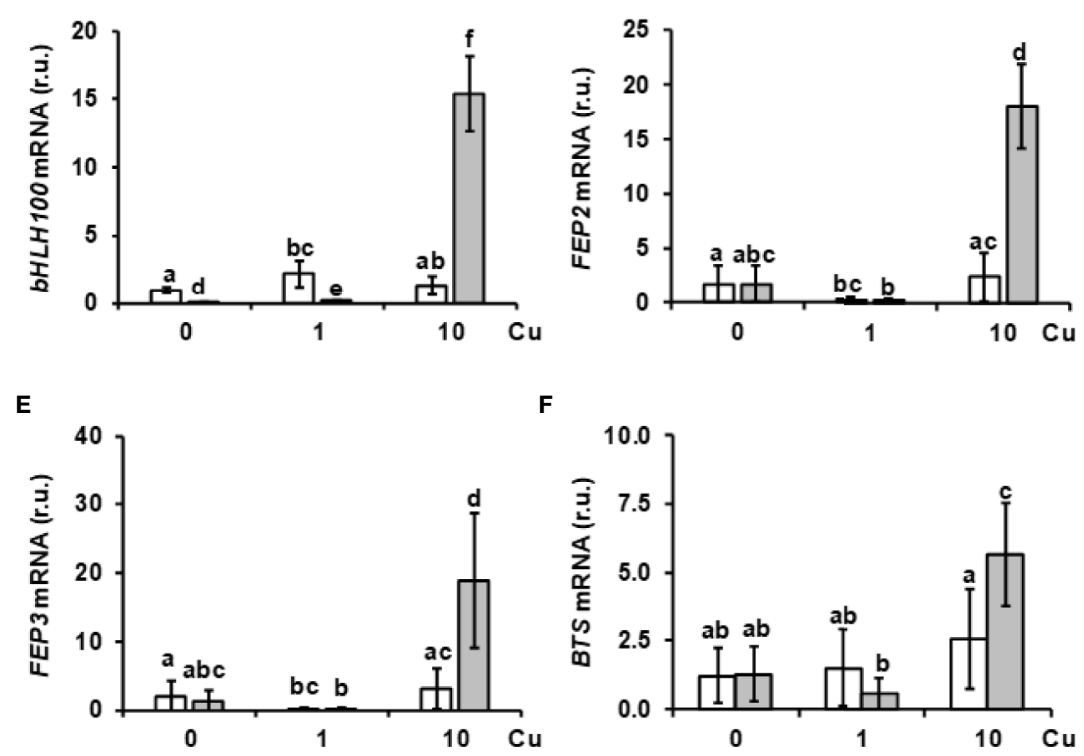

FIGURE 3 | Gene expression of Fe homeostasis regulators in COPT1 ${ }^{O E}$ seedlings. The 7-day-old WT (white bars) and COPT1 ${ }^{O E}$ plants (grey bars) seedlings grown under Cu deficiency $\left(0 \mu \mathrm{M} \mathrm{CuSO}_{4}\right)$, sufficiency $\left(1 \mu \mathrm{M} \mathrm{CuSO}_{4}\right)$ or Cu excess $\left(10 \mu \mathrm{M} \mathrm{CuSO}_{4}\right)$. Expression of FIT (A), bHLH39 (B), bHLH100 (C), FEP2 (D), FEP3 (E), and BTS (F) was determined by RT-qPCR. Gene expression is represented as relative expression levels (r.u.) in relation to the WT under control conditions. UBQ10 was used as housekeeping gene. Bars correspond to arithmetic means $\left(2^{-\Delta \Delta C t}\right) \pm S D$ of biological replicates $(n=3)$. Samples with a letter in common are not significantly different $(p$-value $<0.05)$. 
the opposite regulation in $C O P T 1^{O E}$ seedlings under $\mathrm{Cu}$ excess was observed for FIT and the rest of regulatory $b H L H-I b$ factors. Whereas FIT expression was reduced under $\mathrm{Cu}$ excess in $C O P T^{O E}$ respect to the WT, $b H L H-I b$ expression was increased under $\mathrm{Cu}$ excess (Figure 3 and Supplementary Figure S4).

Among the most induced Fe-related genes in the COPT1 ${ }^{O E}$ line under $\mathrm{Cu}$ excess were the Fe peptide regulators FEP2 and FEP3 (Table 1). The expression of these responds to $\mathrm{Fe}$ deficiency in a FIT-independent manner (Hirayama et al., 2018). In agreement with low Fe levels in the $C O P T 1^{O E}$ plants, FEP2 and FEP3 were clearly induced under $\mathrm{Cu}$ excess (Figures 3D, E). This result indicated that the FIT-independent signaling pathway for FEP2 and FEP3 induction was not affected by deregulated $\mathrm{Cu}$ uptake in $C O P T 1^{O E}$ under $\mathrm{Cu}$ excess.

Taken together these results indicate that strategy I local responses to Fe deficiency cannot take place in $C O P T^{O E}$ seedlings under $\mathrm{Cu}$ excess despite the increased expression in $\mathrm{bHLH}-\mathrm{Ib}$ transcription factors and FEP genes. This is probably due to the inhibition of FIT expression (Figure 3A), whereas the opposite occurs under $\mathrm{Cu}$ deficiency where, despite slightly enhanced FIT expression in the COPT1 ${ }^{O E}$ seedlings, the low bHLH-Ib expression (Figure 3 and Supplementary Figure S4) was precluding assimilatory Fe deficiency responses.

Regarding to upstream regulators of Fe homeostasis that were repressed in $C O P T 1^{O E}$ (Table 1), we analyzed the expression of the subgroup IVc members of bHLH (bHLH105/IRL3 and bHLH115) transcription factors. IRL3 and bHLH115 were repressed in $C O P T 3^{O E}$ (Supplementary Figures S4C, D). On the other hand, BTS expression encoding an E3 ubiquitin ligase that participates in Fe sensing (Long et al., 2010; Kobayashi et al., 2013) was enhanced under $\mathrm{Cu}$ excess in WT plants and further increased in $C O P T 1^{O E}$ (Figure 3F). This increased expression in BTS and the reduced $\mathrm{Fe}$ uptake response under $\mathrm{Cu}$ excess (Figure 1) was according to the BTS role as a negative regulator of $\mathrm{Fe}$ assimilatory responses (Hindt et al., 2017).

Plant hormones are involved in regulating the expression of $\mathrm{Fe}$ deficiency-responsive genes (Kobayashi, 2019). In order to check if hormone contents were significantly affected in $C O P T 1^{O E}$ seedlings, abscisic acid (ABA), jasmonic acid (JA), and indol acetic acid (IAA) contents were determined (Supplementary Figure S5). Whereas the ABA levels were not significantly modified with respect to controls, JA and IAA levels decreased in $C O P T 1^{O E}$ seedlings as $\mathrm{Cu}$ increased in the medium (Supplementary Figure S5).

\section{Phenotype of COPT ${ }^{O E}$ Seedlings Under Fe Deficiency}

Given the previous data, we studied the phenotype of $C O P T^{O E}$ seedlings under Fe deficiency (Figure 4). Thus, 7-day-old WT, $C O P T 1^{O E}$, and $C O P T 3^{O E}$ seedlings were grown in media with $\mathrm{Fe}$ sufficiency $(50 \mu \mathrm{M} \mathrm{FeSO}$ ) and slight Fe deficiency $(10 \mu \mathrm{M}$ $\mathrm{FeSO}_{4}$ ) (Figure 4). Whereas WT seedlings increased their root length under slight Fe deficiency conditions, $C O P T^{O E}$ presented a similar length of their roots in both media (Figures 4A, B). Root shortening in the $C O P T^{O E}$ with respect to WT under slight
A

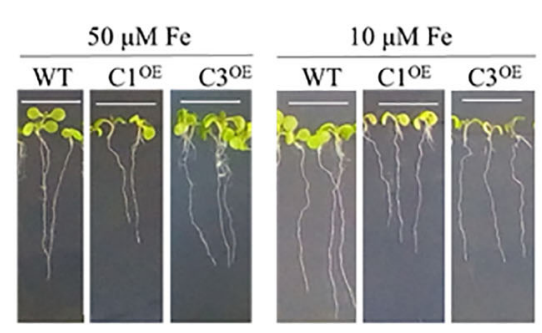

C

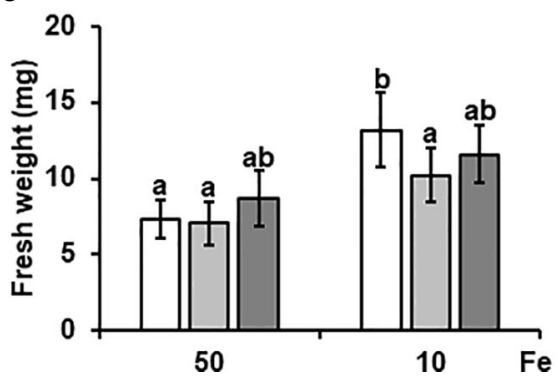

B

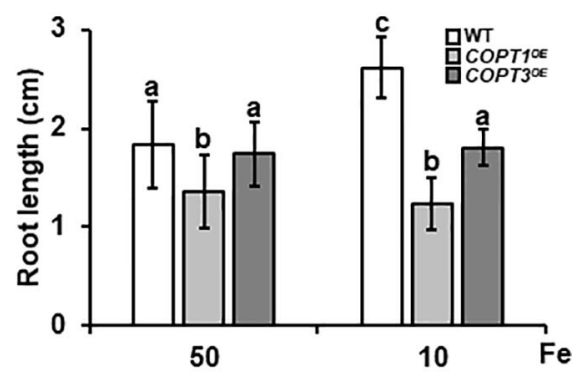

D

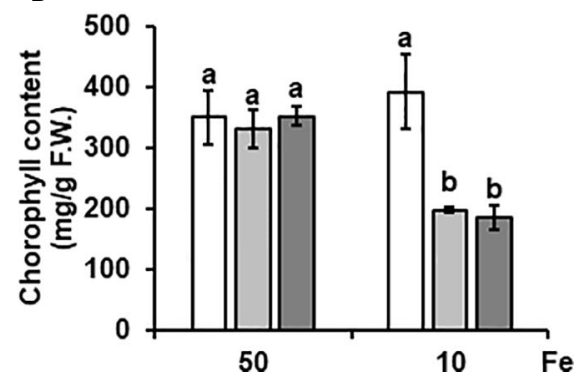

FIGURE 4 | Physiological characterization of $C O P T^{O E}$ seedlings under Fe deficiency. (A) Representative photographs of 7-day-old seedlings of WT, COPT1 ${ }^{O E}$ and COPT3 ${ }^{\mathrm{OE}}$ under Fe sufficiency $\left(50 \mu \mathrm{M} \mathrm{FeSO}_{4}\right)$ or slight Fe deficiency $(10 \mu \mathrm{M} \mathrm{FeSO} 4)$. White scale bars represent $1 \mathrm{~cm}$. (B) Root length of the of WT (white bars), $\mathrm{COPT}^{\mathrm{OE}}$ (light grey bars), and COPT3 ${ }^{\mathrm{OE}}$ (dark grey bars) under the same growth conditions as in (A). (C) Fresh weight of 5 WT and COPT1 ${ }^{O E}$ seedlings grown under the same conditions as in (A). (D) Total chlorophyll content of WT and COPT ${ }^{O E}$ seedlings grown under the same conditions as in (A). Bars correspond to arithmetic means $\left(2^{-\Delta \Delta C t}\right) \pm S D$ of biological replicates $(n=3)$. Samples with a letter in common are not significantly different $(p$-value $<0.05)$. 
Fe deficiency was around 50\%. No changes were observed in the seedlings fresh weight under sufficiency, while under slight $\mathrm{Fe}$ deficiency, the weight was reduced in $C O P T 1^{O E}$ (Figure 4C). Moreover, the total chlorophyll content did not show significant changes in the WT, while COPT ${ }^{O E}$ seedlings displayed around $50 \%$ lower chlorophyll content in Fe deficiency (Figure 4D). Taken together, these data indicate that $C O P T^{O E}$ seedlings are more sensitive to slight Fe deficiency conditions than WT.

Then, we analyzed the expression of Fe homeostasis-related genes under Fe sufficiency and deficiency. IRT1 expression increased under Fe deficiency in both WT and COPT ${ }^{O E}$ (Supplementary Figure S6A). On the other hand, an increase in FIT expression was observed under Fe deficiency in the WT plants, while in $C O P T^{O E}$ this increase was exacerbated (Supplementary Figure S6B). Furthermore, FEP2 and FEP3 expression was induced in WT plants under Fe deficiency but it was also highly increased in $\mathrm{COPT1}^{\mathrm{OE}}$ (Supplementary Figures S6C, D). Taken together, these results indicated that $C O P T^{O E}$ seedlings properly responded to Fe deficiency under $\mathrm{Cu}$ sufficiency and that their defects in Fe homeostasis were restricted to $\mathrm{Cu}$ deficiency and excess conditions.

The expression of the Fe homeostasis regulators FIT, bHLH38, bHLH100, and UPB1 was analyzed under different metal deficiency and excess conditions in the WT plants (Supplementary Figure S7). FIT, bHLH38, and bHLH100 where induced under $\mathrm{Fe}$ deficiency whereas UPB1 was repressed. Curiously, all of them but FIT were regulated in the same sense under $\mathrm{Cu}$ excess and Fe deficiency, either induced (bHLH38 and $b H L H 100)$ or repressed (UPB1), suggesting that maybe there are certain similarities or common steps in signal transduction between the responses to $\mathrm{Cu}$ excess and Fe deficiency, leading to the induction of these transcriptional factors.

\section{Expression of Genes Involved in Tetrapyrrole Biosynthesis in COPT ${ }^{O E}$ Seedlings}

GO analysis of the global transcriptomic analysis revealed that the chloroplast was the subcellular compartment most affected in $C O P T 1^{O E}$ (Supplementary Table SV). GO categories differentially enriched among genes differentially regulated in $C O P T 1^{O E}$ seedlings were photosynthesis-associated nuclear genes $(P h A N G)$ and genes related to photomorphogenesis, and oxidative stress (Table 1 and Supplementary Tables SIII and $\mathbf{S V})$. Therefore, we decided to assess the alteration of the expression of genes in the tetrapyrrole biosynthesis pathway and the retrograde signaling components (Table 1). The LHCB2.3 expression, a representant among the multiple $P h A N G$, which are down-regulated in the COPT1 ${ }^{O E}$ seedlings

(Table SII), was confirmed to be repressed (Figure 5A). Moreover, the expression of GUN4, a regulator of the plastidic tetrapyrrole signaling (Davison et al., 2005), was also repressed in most conditions (Figure 5B). In addition, CHL27/CDR1 (Bang et al., 2008) was also down-regulated in $C O P T^{O E}$ seedlings (Figure 5C), further confirming the involvement of tetrapyrrole signaling in $\mathrm{Cu}$-dependent $\mathrm{Fe}$ deficiency responses. The regulation of a chloroplastic sigma factor SIG1 involved in retrograde signaling (Macadlo et al., 2019) was also downregulated under $\mathrm{Cu}$ deficiency in $C O P T^{O E}$ seedlings
A

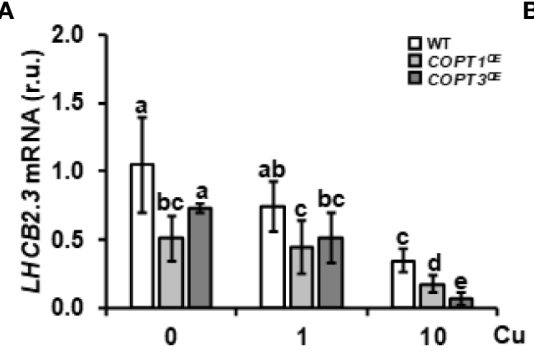

C

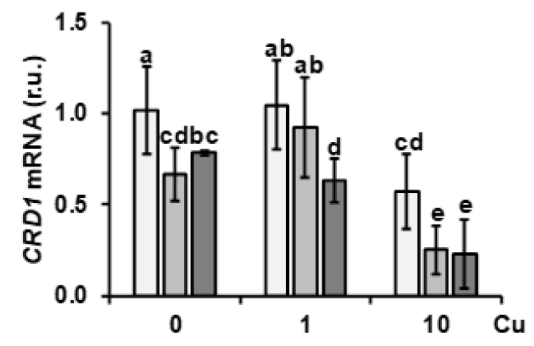

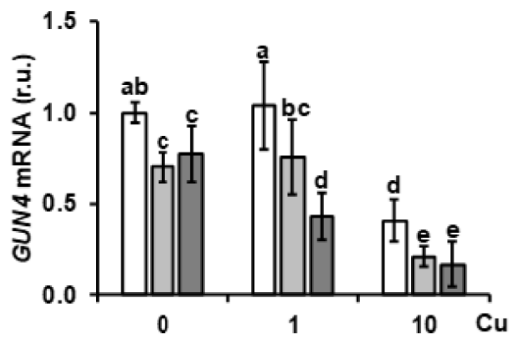

D

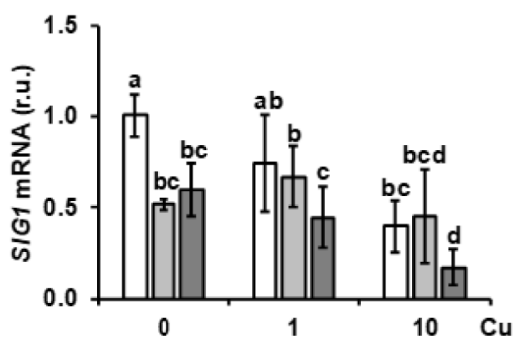

FIGURE 5 | Expression of genes related to tetrapyrrole biosynthesis and retrograde signaling in COPT ${ }^{O E}$. Expression of the LHCB2.3 (A), GUN4 (B), CDR1 (C), and SIG1A (D) genes in WT (white bars), COPT1 ${ }^{\mathrm{OE}}$ (light grey bars), and COPT3 ${ }^{\mathrm{OE}}$ (dark grey bars) seedlings grown under Cu deficiency $\left(0 \mu \mathrm{M}\right.$ CuSO $\left.{ }_{4}\right)$, sufficiency $(1 \mu \mathrm{M}$ $\left.\mathrm{CuSO}_{4}\right)$ or Cu excess $\left(10 \mu \mathrm{M} \mathrm{CuSO}_{4}\right)$ was determined by RT-qPCR. Gene expression is represented as relative expression levels (r.u.) in relation to the WT under control conditions. UBQ10 was used as housekeeping gene. Bars correspond to arithmetic means $\left(2^{-\Delta \Delta C t}\right) \pm S D$ of biological replicates $(n=3)$. Samples with a letter in common are not significantly different $(p$-value $<0.05)$. 
(Figure 5D). Taken together, these results indicated that the tetrapyrrole signaling pathway was affected under both $\mathrm{Cu}$ deficiency and excess, probably as a consequence of the common Fe deficiency conditions faced by $C O P T^{O E}$ seedlings.

\section{Root Respiration and Oxidative Stress in COPT ${ }^{O E}$ Seedlings}

Since the respiratory electron transport chain is one of the most metal requiring processes, $\mathrm{O}_{2}$ consumption was measured in 7day-old roots of $\mathrm{WT}$ and $\mathrm{COPT} 1^{\mathrm{OE}}$ seedlings grown in deficiency $\left(0 \mu \mathrm{M} \mathrm{CuSO}_{4}\right)$, sufficiency $\left(1 \mu \mathrm{M} \mathrm{CuSO}_{4}\right)$ and excess $\mathrm{CuSO}_{4}(10$ $\mu \mathrm{M} \mathrm{CuSO}_{4}$ ) (Figure 6A). The results showed that $\mathrm{O}_{2}$ consumption in WT seedlings did not exhibit significant changes between the three media, while $C O P T 1^{O E}$ displayed lower $\mathrm{O}_{2}$ consumption when the $\mathrm{Cu}$ conditions were not optimal, in both deficiency and in excess, with a decrease of 42 and $46 \%$ respectively, compared to WT (Figure 6A). In agreement with a defective functioning of the respiratory electron transport chain, expression of the ALTERNATIVE OXIDASE $1 D(A O X-1 D)$, aimed to restore electron flow in a non-phosphorylating bypass (Clifton et al., 2006; Selinski et al., 2018), was increased in COPT1 ${ }^{O E}$ (Figure 6B). Moreover, other $A O X$ genes, such as $A O X 1 A(+2.46)$ and $A O X 2(+2.08)$, were also induced under $\mathrm{Cu}$ excess in $C O P T^{O E}$ (Supplementary Table SI). On the other hand, expression of the $L O W$ SULPHUR UPREGULATED1 (LSU1) has been shown to prevent chloroplastic ROS production by interacting with FSD2 (Garcia-Molina et al., 2017). LSU1 was also greatly induced under $\mathrm{Cu}$ excess (Figure 6C), as well as LSU2 and LSU3 (Supplementary Table SI). Inhibition of FSD1 and CSD2 expression in the $C O P T^{O E}$ plants (Supplementary Figure S3) suggested a defective antioxidant capacity by an increase in the radical superoxide $\left(\mathrm{O}_{2}{ }^{-}\right)$and a decrease in hydrogen peroxide $\left(\mathrm{H}_{2} \mathrm{O}_{2}\right)$.

UPB1 spatially regulates ROS distribution in the root transition zone where the balance between $\mathrm{O}_{2}{ }^{--}$and $\mathrm{H}_{2} \mathrm{O}_{2}$ controls the transition between root cell proliferation and differentiation (Tsukagoshi et al., 2010). UPB1 expression was induced under $\mathrm{Cu}$ deficiency and sufficiency in $C O P T 1^{O E}$ seedlings compared to WT (Figure 6D). Accordingly, two of its direct targets, PER39 and PER40, were also up-regulated under $\mathrm{Cu}$ deficiency (Supplementary Figures S8A, B). Furthermore, UBP1 expression under different metal stress conditions in the WT indicated that was repressed under $\mathrm{Cu}$ excess as well as when Fe is low (Supplementary Figure S7D). These responses indicated clearly different responses of $\mathrm{Fe}$ regulators to low and high $\mathrm{Cu}$ levels.

Since these results would lead to a further decrease in $\mathrm{H}_{2} \mathrm{O}_{2}$, seedlings were grown in $\mathrm{Cu}$-deficient media in the presence of $\mathrm{H}_{2} \mathrm{O}_{2}$ and the reductants ascorbic acid (AsH) and 1,4ditiothreitol (DTT) (Supplementary Figure S9). COPT1 ${ }^{O E}$ seedlings showed shorter roots than controls under $\mathrm{Cu}$
A

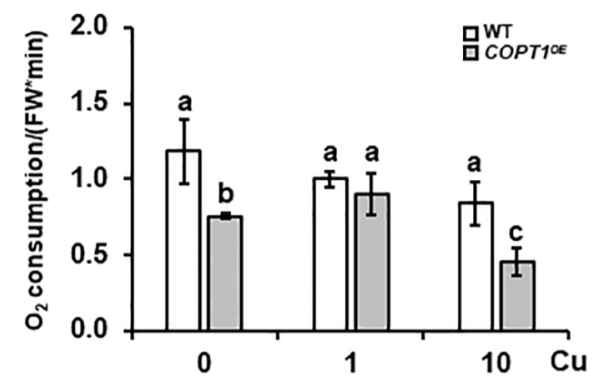

C

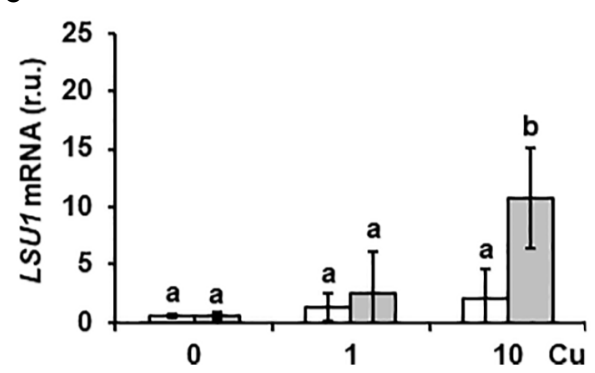

B

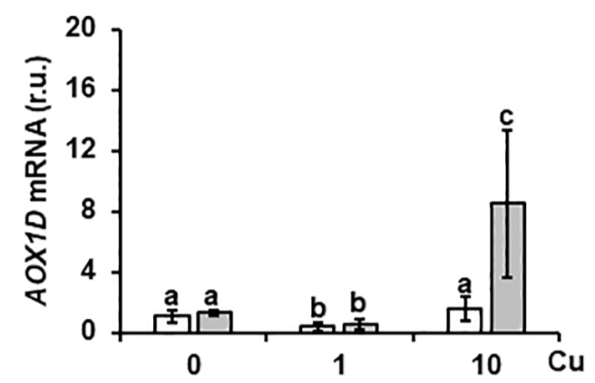

。

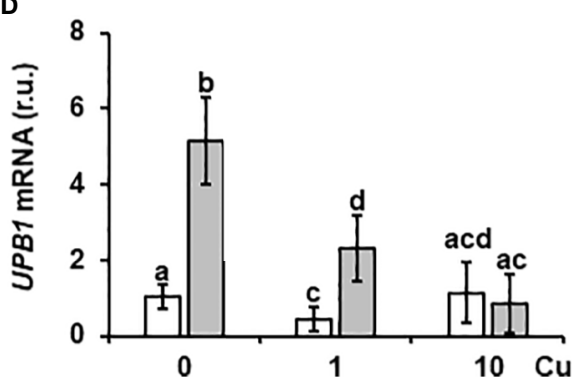

FIGURE 6 | Root $\mathrm{O}_{2}$ consumption and expression of stress-related genes in COPT1 ${ }^{O E}$. (A) $\mathrm{O}_{2}$ consumption in roots of 10-day-old WT and COPT1 ${ }^{O E}$ seedlings cultivated with different $\mathrm{CuSO}_{4}$ concentrations. The rate of $\mathrm{O}_{2}$ decrease was referenced to roots F.W. (nmol $\mathrm{O}_{2} / \mathrm{OD} 600$ * F.W). The values represented are the arithmetic mean $\pm \mathrm{SD}$ of $\mathrm{n}=3$ biological replicates. Expression of the AOX-1D (B), LSU1 (C), and UPB1 (D) genes in WT (white bars) and COPT1OE (grey bars) seedlings grown under $\mathrm{Cu}$ deficiency $\left(0 \mu \mathrm{M} \mathrm{CuSO}_{4}\right)$, sufficiency $\left(1 \mu \mathrm{M} \mathrm{CuSO}_{4}\right)$ or Cu excess $\left(10 \mu \mathrm{M} \mathrm{CuSO}_{4}\right)$ was determined by RT-qPCR. Gene expression is represented as relative expression levels (r.u.) in relation to the WT under control conditions. UBQ10 was used as housekeeping gene. Bars correspond to arithmetic means $\left(2^{-\Delta \Delta C t}\right) \pm S D$ of biological replicates $(n=3)$. Samples with a letter in common are not significantly different $(p$-value $<0.05)$. 
deficiency. Whereas no clear effects were observed on root length for the $\mathrm{H}_{2} \mathrm{O}_{2}$ treatment, reductants such as AsH and DTT, improved the root growth of $C O P T 1^{O E}$ compared to WT (Supplementary Figure S9) further pointing to increased oxidative stress in the overexpressing line under $\mathrm{Cu}$ deficiency.

Additionally, since the Fe content was lower in $C O P T^{O E}$, a Fe excess treatment was also provided with no differential effect compared to controls (Supplementary Figure S9). In order to ascertain the Fe redox state in the roots, 7-day-old seedlings grown in the same media with different $\mathrm{Cu}$ content $(0,1$, and 10 $\mu \mathrm{M} \mathrm{CuSO}$ ) were stained with the Perl's blue to detect the presence of $\mathrm{Fe}^{3+}$. The intensity of stained roots indicated that $\mathrm{Fe}^{3+}$ increased as $\mathrm{Cu}$ rise in the media from 0 to $10 \mu \mathrm{M} \mathrm{Cu}$ in all seedlings' genotypes. Moreover, $C O P T^{O E}$ seedlings were more intensely stained than WT in all the conditions (Figure 7) and this result is reproducible in 11-day-old seedlings (Supplementary Figure S10), indicating that $\mathrm{Cu}^{+}$uptake through COPT is affecting the redox state of incorporated Fe leading to an increase in the $\mathrm{Fe}^{3+} / \mathrm{Fe}^{2+}$ ratio in the $C O P T^{O E}$ roots since the lower total $\mathrm{Fe}$ concentration (Figure 1D).

These results suggested that the reduction in $\mathrm{Fe}$ content observed in $\mathrm{COPT}^{\mathrm{OE}}$ could be due to the increased $\mathrm{Fe}^{3+} / \mathrm{Fe}^{2+}$ ratio when $\mathrm{Cu}^{+}$entrance was enhanced and deregulated in $C O P T^{O E}$ seedlings. Thus, a model for the $\mathrm{Cu}$ excess effects on $\mathrm{Fe}$ homeostasis in $C O P T^{O E}$ seedlings has been proposed (Figure 8). The deregulated $\mathrm{Cu}^{+}$entrance in $C O P T^{O E}$ plants under high $\mathrm{Cu}$ activated the expression of the $b H L H-I b$ factors but not FIT. This effect redounded in Fe deficiency symptoms in $C O P T^{O E}$ probably as a consequence of the lack of Fe assimilatory response. $\mathrm{Cu}$ excess increased the $\mathrm{Fe}^{3+} / \mathrm{Fe}^{2+}$ ratio in $C O P T^{O E}$ roots, probably leading to signaling pathways that could further inhibit Fe uptake.

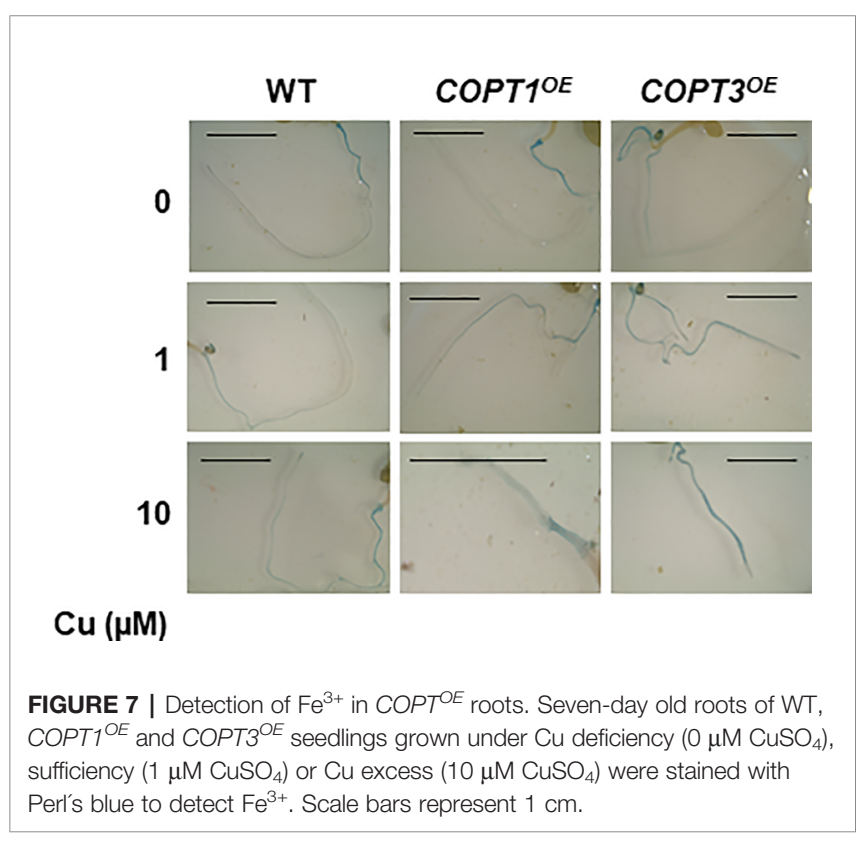

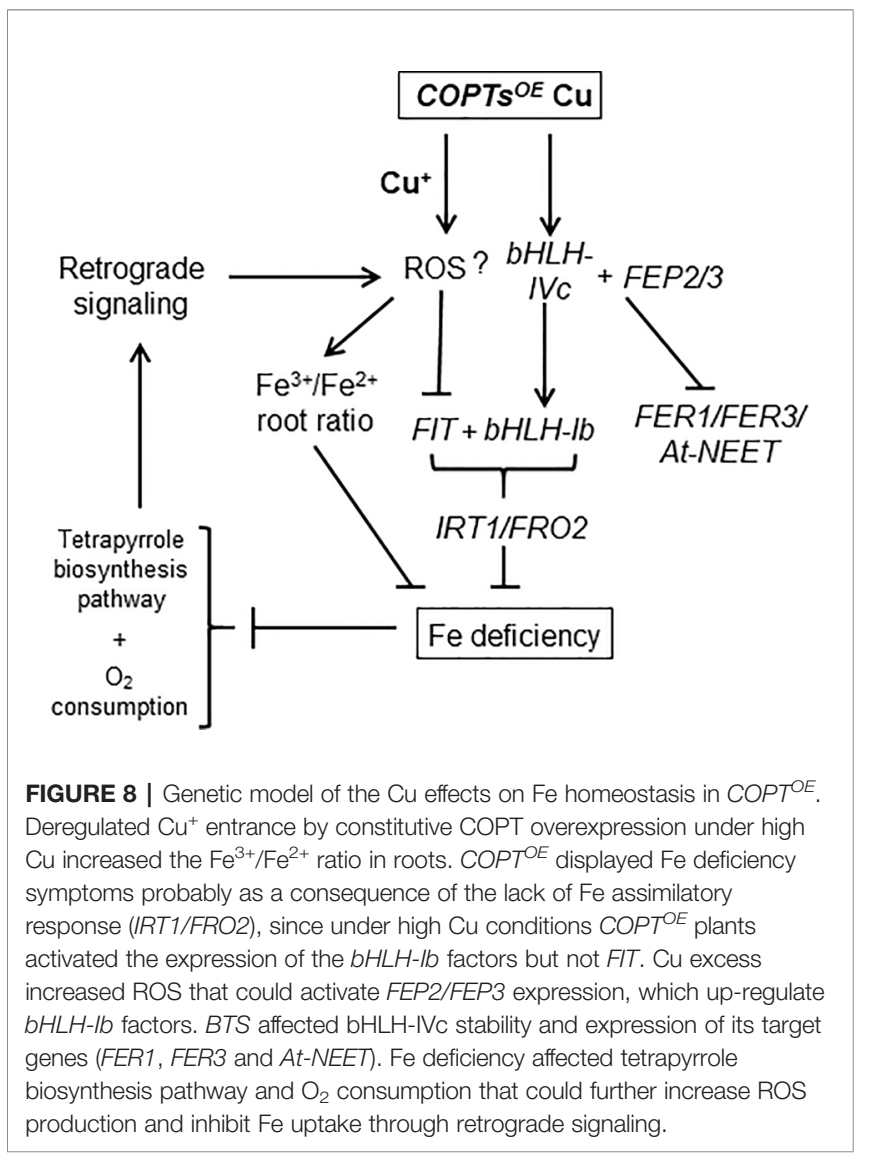

\section{DISCUSSION}

In this report, we studied the effects of deregulated $\mathrm{Cu}^{+}$entrance in $C O P T^{O E}$ seedlings, which overexpress COPT $\mathrm{Cu}$ transporters (Andrés-Colás et al., 2010), on global gene expression when seedlings were grown in $\mathrm{Cu}$ concentrations within the physiological range that plants encounter in their natural environment. Our results indicate that $\mathrm{Fe}$ transport and homeostasis were altered in $C O P T^{O E}$. Despite containing low $\mathrm{Fe}, C O P T^{O E}$ was not able to orchestrate an optimal local Feuptake response at their roots under both $\mathrm{Cu}$ deficiency and excess (Figure 1). The causes for the $\mathrm{Cu}$ interference with the $\mathrm{Fe}$ uptake response seem different in both conditions. Under $\mathrm{Cu}$ deficiency, $C O P T^{O E}$ induced FIT, but the expression of subgroup $\mathrm{Ib}$ of $b H L H$ remained low. On the contrary, under $\mathrm{Cu}$ excess, FIT was repressed, despite high FEPs and $b H L H-I b$ expression (Figure 3). Based on the necessity of expressing both FIT and subgroup Ib of bHLH transcription factors for Fe-uptake responses (Yuan et al., 2008; Wang et al., 2013), COPT ${ }^{O E}$ seedlings were unable to properly respond to Fe deficiency under non-optimal $\mathrm{Cu}$ supply.

$\mathrm{Fe}$ and $\mathrm{Cu}$ homeostasis interact at different levels in plants (Puig et al., 2007; Bernal et al., 2012; Perea-García et al., 2013; Kastoori Ramamurthy et al., 2018). For instance, high $\mathrm{Cu}$ 
concentrations in the media lower leaf Fe content (Waters et al., 2012; Waters and Armbrust, 2013). In our experimental conditions, a slight decrease in IRT1 expression was observed in the WT seedlings under $\mathrm{Cu}$ excess, which was further exacerbated in $C O P T^{O E}$. On the other hand, higher $\mathrm{Cu}$ content was observed under Fe deficiency in WT (Kastoori Ramamurthy et al., 2018). Among the reasons for increased $\mathrm{Cu}$ content under Fe deficiency are the increased uptake of both the unspecific $\mathrm{Cu}^{2+}$ entrance through ZIP transporters and the specific $\mathrm{Cu}^{+}$entrance through COPT2 (Colangelo and Guerinot, 2004; Perea-García et al., 2013). Nevertheless, the reason for $\mathrm{Cu}^{+}$requirement under Fe deficiency remains unsolved.

Although recent data suggested that Fe deficiency responses are under the control of SPL7 (Kastoori Ramamurthy et al., 2018), Cu-dependent SPL7-mediated responses did not seem to be the cause of IRT1 down-regulation in COPT ${ }^{O E}$ since the expression of other SPL7 target genes was not significantly affected in these plants. On the other hand, different hormones are involved in modulating Fe deficiency responses in plants (Kobayashi, 2019). JA has been shown to inhibit the expression of $b H L H-I b$ and promote FIT degradation, resulting in reduced expression of the Fe uptake genes IRT1 and FRO2 and increased sensitivity to Fe deficiency (Cui et al., 2018). Since JA is a negative regulator of $\mathrm{Fe}$ deficiency responses and JA content was reduced in $C O P T 1^{O E}$, lower levels of JA could not justify the decrease in $\mathrm{Fe}$ uptake under our experimental conditions. However, auxins can enhance FIT and FRO2 expression (Chen et al., 2010), and, in this sense, we cannot discard that IAA decreased levels in $C O P T 1^{O E}$ seedlings under $\mathrm{Cu}$ excess could at least partially account for the low FIT expression in $C O P T 1^{O E}$ plants.

The oxidative stress produced by metal deficiencies and excess could also account for the $\mathrm{Fe}$ and $\mathrm{Cu}$ crosstalk (Ravet and Pilon, 2013). Indeed, $\mathrm{Cu}$ phytotoxicity has been attributed to increased $\mathrm{H}_{2} \mathrm{O}_{2}$ production (Cuypers et al., 2010) and the deficiency of $\mathrm{Cu}$ affects the functioning of the respiratory and photosynthetic electron transport chains, which increases the production of the $\mathrm{O}_{2}{ }^{--}$(Abdel-Ghany et al., 2005; Yamasaki et al., 2009). Therefore, the majority type of ROS could be different under conditions of metal deficiency or excess. Increased oxidative stress leading to lipid peroxidation has been previously reported to occur in $C O P T^{O E}$ seedlings (AndrésColás et al., 2010). According to the slightly increased $\mathrm{Cu}$ content in $C O P T^{O E}$ seedlings (Andrés-Colás et al., 2010), they should have increased CSD2 levels under $\mathrm{Cu}$ excess, instead of the observed lower levels. This result suggests a difficulty of the $C O P T^{O E}$ chloroplasts in detoxifying $\mathrm{O}_{2}{ }^{--}$under $\mathrm{Cu}$ excess, since they cannot completely activate neither FSD1 nor CSD2 compared to the WT, maybe redounding in increased oxidative stress. The induction of several members of the LSU family (LSU1, LSU2 and LSU3) under $\mathrm{Cu}$ excess in the $C O P T^{O E}$ plants is in agreement with their induction under sulfur deficiency and by Fe deficiency and $\mathrm{Cu}$ excess (GarciaMolina et al., 2017). LSU1 interacts with chloroplastic FSD2 and stimulates its enzymatic activity in vivo and in vitro conforming a hub in coordinating plant responses to a wide spectrum of abiotic stress conditions (Garcia-Molina et al., 2017). Moreover, COPT1 ${ }^{O E}$ seedlings showed higher $\mathrm{Cu}$ induced $\mathrm{K}^{+}$efflux and net $\mathrm{Ca}^{2+}$ influx at the root tip level compared to the WT (Rodrigo-Moreno et al., 2013), although no significant changes of the membrane potential were detected upon $\mathrm{Cu}$ addition (Sanz et al., 2019).

Although increased $\mathrm{O}_{2}$ consumption has been also reported in sugar beet and cucumber roots (Lopez-Millan et al., 2000; Vigani et al., 2009), the ability to consume $\mathrm{O}_{2}$ decreased in $C O P T 1^{O E}$ roots under both $\mathrm{Cu}$ deficiency and excess (Figure 6A). High $\mathrm{Cu}$ in $C O P T 1^{O E}$ triggers a response that includes the expression of genes related to mitochondrial stress (ArnholdtSchmitt et al., 2006; Selinski et al., 2018), such as AOX1A, $A O X 1 D$ and $A O X 2$. Results shown here support the respiratory shield hypothesis, where the mitochondrial $\mathrm{Fe}$ proteins are necessary to maintain high $\mathrm{O}_{2}$ consumption in the respiratory electron transport chain contributing to the microaerobic environment necessary to maintain a $\mathrm{Fe}^{2+}$ pool. The problem due to lack of respiratory shield could be aggravated in conditions of Fe deficiency and high and temporarily deregulated $\mathrm{Cu}^{+}$entry. In this sense, the defect of $\mathrm{Fe} / \mathrm{S}$ and heme proteins will lead to defective respiratory shield in strains with high metabolism (López-Torrejón et al., 2016; Wofford et al., 2019), aggravated in COPT1 ${ }^{O E}$ seedlings by deregulated $\mathrm{Cu}^{+}$uptake. In any case, our observations support that optimal $\mathrm{Cu}$ supply is required for normal $\mathrm{O}_{2}$ consumption in $C O P T 1^{O E}$ plants.

$\mathrm{Cu}$ deficiency affects $\mathrm{Fe}$ homeostasis specifically causing a defect in root-to-shoot translocation, which has been attributed to a decrease in $\mathrm{Cu}$-dependent ferroxidase activity (Bernal et al., 2012; Waters and Armbrust, 2013). Assuming that a certain $\mathrm{Fe}^{3+} / \mathrm{Fe}^{2+}$ and $\mathrm{Cu}^{2+} / \mathrm{Cu}^{+}$intracellular ratios are necessary for uptake/mobilization processes, $\mathrm{Cu}^{+}$uptake could affect the $\mathrm{Fe}^{3+}$ / $\mathrm{Fe}^{2+}$ ratio at different levels. Firstly, due to its lower standard reduction potential, $\mathrm{Cu}^{+}$could directly reduce $\mathrm{Fe}^{3+}$ to $\mathrm{Fe}^{2+}$. However, this is not the case since increased $\mathrm{Fe}^{3+}$ was observed in $C O P T^{O E}$ seedlings (Figure 7). Moreover, highly reactive, cytosolic free $\mathrm{Cu}^{+}$is almost absent in the cytosol (Rae et al., 1999). Instead, increased oxidative stress provoked by deregulated $\mathrm{Cu}^{+}$entrance (Rodrigo-Moreno et al., 2013) could influence intracellular general redox status, leading to $\mathrm{Fe}$ oxidation. On the other hand, $\mathrm{Cu}$ deficiency would facilitate $\mathrm{Fe}^{2+}$ incorporation through the enhanced expression of FRO metalloreductases and inhibit $\mathrm{Cu}$-dependent ferroxidase activity (Bernal et al., 2012; Waters et al., 2012; Waters and Armbrust, 2013). Since the $\mathrm{Fe}^{3+} / \mathrm{Fe}^{2+}$ ratio depends on the relative ferroxidase versus ferroreductase activities, an increased $\mathrm{Fe}^{3+} /$ $\mathrm{Fe}^{2+}$ ratio would be expected in the presence of excess $\mathrm{Cu}$. The other way around, the $\mathrm{Fe}^{3+} / \mathrm{Fe}^{2+}$ ratio should be decreased under $\mathrm{Cu}$ deficiency. Under our experimental conditions, we were not able to detect a significant change in ferroreductase activity and just a slight decrease is observed in $C O P T^{O E}$ seedlings under $\mathrm{Cu}$ excess (Figure 1B), questioning this activity being the only cause of the $\mathrm{Fe}$ deficiency. Finally, $\mathrm{Cu}$ uptake increased $\mathrm{Fe}^{3+}$ in the roots, probably by means of the oxidative conditions created. As a consequence, decreased Fe mobilization in roots could lead to 
Fe deficiency in leaves. In this sense, $\mathrm{Cu}$ excess and deregulated $\mathrm{Cu}^{+}$ uptake in $C O P T^{O E}$ seedlings increased the $\mathrm{Fe}^{3+} / \mathrm{Fe}^{2+}$ ratio leading to Fe deficiency effects, being it at least one of the problems faced by $\mathrm{Cu}^{+}$toxicity (Figure 8). Accordingly, this suggestion could explain previous results where plants grown without $\mathrm{Fe}$ were more susceptible to $\mathrm{Cu}$ toxicity (Waters and Armbrust, 2013).

In order to address how $\mathrm{Cu}$ influenced the signaling pathways involved in the Fe deficiency response, the expression of BTS and several other genes encoding RING E3 ubiquitin ligases were induced in the $C O P T 1^{O E}$ seedlings. This result points to the putative Fe-sensing BTS (Selote et al., 2015), and maybe other RING E3 ubiquitin ligases, as candidates in upstream sensing of the lack of $\mathrm{Fe}$ mobilization in $C O P T 1^{O E}$ plants under mild $\mathrm{Cu}$ excess. On the other hand, our results indicated that tetrapyrrole signaling was affected under both $\mathrm{Cu}$ deficiency and excess, probably as a consequence of the common Fe deficiency conditions faced by $C O P T^{O E}$ seedlings (Supplementary Tables SIII and SIV). Most of the genes involved in tetrapyrrole metabolism showed synchronized and light-dependent expression patterns (Matsumoto et al., 2004). Multiple PhANG were down-regulated in $C O P T 1^{O E}$ under both $\mathrm{Cu}$ deficiency and excess in addition to several regulators. Curiously, CHL27/CRD1 (COPPER RESPONSE DEFECT1) was first characterized in a screening for $\mathrm{Cu}$ conditional phenotypes in Chlamydomonas where $\mathrm{Cu}$ scarcity in plastocyanin is counteracted by a hemecontaining cytochrome (Moseley et al., 2000), although this substitution has not been shown to occur in Arabidopsis. Moreover, the GUN4 porphyrin-binding protein enhances Mgchelatase activity (Davison et al., 2005) and its repression under $\mathrm{Cu}$ excess could play a role in the control of substrate flow into the heme or chlorophyll branch (Tanaka and Tanaka, 2007). On the other hand, nuclear-encoded sigma factor, such as SIG1, could be involved in the integration of light and circadian signals that regulate chloroplast transcription (Belbin et al., 2017). These results underscore the importance of tightly regulated $\mathrm{Cu}$ homeostasis at the spatial-temporal level, in order to orchestrate an optimal Fe distribution and to avoid oxidative damage to highly sensitive Fe-dependent processes, such as $\mathrm{Fe} / \mathrm{S}$ cluster assembly and tetrapyrrole biosynthesis. It is tempting to speculate that Fe and other metals, which affect at the cellular redox state and either participate or interfere with sensitive processes, have to be subjected to differential diurnal variation in the expression patterns of their homeostatic components (Peñarrubia et al., 2015; Zhang and Krämer, 2018). In this sense, the induced expression of UPB1 in COPT ${ }^{O E}$ plants under $\mathrm{Cu}$ deficiency could emphasize the requirement of spatially appropriate $\mathrm{Cu}$ uptake at the root tip, where normally COPT1 is expressed (Sancenón et al., 2003), to avoid oxidative interference along the root with Fe translocation to the aerial part (Tsukagoshi et al., 2010).

\section{REFERENCES}

Abdel-Ghany, S. E., Burkhead, J. L., Gogolin, K. A., Andres-Colas, N., Bodecker, J. R., Puig, S., et al. (2005). AtCCS is a functional homolog of the yeast copper chaperone Ccs1/Lys7. FEBS Lett. 579, 2307-2312. doi: 10.1016/j.febslet.2005. 03.025
Taken together, these results indicated that high $\mathrm{Cu}$ renders increased $\mathrm{Fe}^{3+}$ in the root. Despite low $\mathrm{Fe}$ in the shoot, the presence of high $\mathrm{Fe}^{3+} / \mathrm{Fe}^{2+}$ ratio in the root prevented local responses to Fe deficiency (Figure 8). The understanding of $\mathrm{Cu}$ influence on $\mathrm{Fe}$ mobilization and redistribution in the plant could help to ameliorate field treatments to maximize crop production under Fe deficiency through optimizing $\mathrm{Cu}$ homeostasis.

\section{DATA AVAILABILITY STATEMENT}

The datasets generated for this study can be found in the: The microarray raw data were deposited in the NCBI's Gene Expression Omnibus and are accessible through GEO Series accession number GSE143857.

\section{AUTHOR CONTRIBUTIONS}

LP and SP conceived the idea and wrote the manuscript. MP-A and FV-S performed the COPT1 ${ }^{O E}$ global analysis. AP-G and AA-B performed the physiological and molecular experiments in mutant plants. All authors contributed to the article and approved the submitted version.

\section{FUNDING}

This work was supported by grant BIO2017-87828-C2-1-P from the Spanish Ministry of Economy and Competitiveness, and by FEDER funds from the European Union.

\section{ACKNOWLEDGMENTS}

We acknowledge the SCSIE (Universitat de València) for the ICPMS service, and the Plant Hormone Quantification Service of the (IBMCP) (CSIC-UPV, Valencia) for hormone level quantification. This work was supported by grant BIO201787828-C2-1-P from the Spanish Ministry of Economy and Competitiveness, and by FEDER funds from the European Union.

\section{SUPPLEMENTARY MATERIAL}

The Supplementary Material for this article can be found online at: https://www.frontiersin.org/articles/10.3389/fpls.2020.01106/ full\#supplementary-material

Andrés-Bordería, A., Andrés, F., Garcia-Molina, A., Perea-García, A., Domingo, C. Puig, S., et al. (2017). Copper and ectopic expression of the Arabidopsis transport protein COPT1 alter iron homeostasis in rice (Oryza sativa L.). Plant Mol. Biol. 95, 17-32. doi: 10.1007/s11103-017-0622-8

Andrés-Colás, N., Sancenón, V., Rodríguez-Navarro, S., Mayo, S., Thiele, D. J., Ecker, J. R., et al. (2006). The Arabidopsis heavy metal P-type ATPase HMA5 
interacts with metallochaperones and functions in copper detoxification of roots. Plant J. 45, 225-236. doi: 10.1111/j.1365-313X.2005.02601.x

Andrés-Colás, N., Perea-García, A., Puig, S., and Peñarrubia, L. (2010). Deregulated copper transport affects Arabidopsis development especially in the absence of environmental cycles. Plant Physiol. 153, 170-184. doi: 10.1104/ pp.110.153676

Andrés-Colás, N., Carrió-Seguí, A., Abdel-Ghany, S. E., Pilon, M., and Peñarrubia, L. (2018). Expression of the intracellular COPT3-mediated $\mathrm{Cu}$ transport is temporally regulated by the TCP16 transcription factor. Front. Plant Sci. 9:910. doi: $10.3389 /$ fpls.2018.00910

Arnholdt-Schmitt, B., Costa, J. H., and de Melo, D. F. (2006). AOX - a functional marker for efficient cell reprogramming under stress? Trends Plant Sci. 11, 281-287. doi: 10.1016/j.tplants.2006.05.001

Ashburner, M., Ball, C. A., Blake, J. A., Botstein, D., Butler, H., Cherry, J. M., et al. (2000). Gene Ontology: tool for the unification of biology. Nat. Genet. 25, 2529. doi: $10.1038 / 75556$

Bang, W. Y., Jeong, I. S., Kim, D. W., Im, C. H., Ji, C., Hwang, S. M., et al. (2008). Role of Arabidopsis CHL27 protein for photosynthesis, chloroplast development and gene expression profiling. Plant Cell Physiol. 49, 13501363. doi: $10.1093 / \mathrm{pcp} / \mathrm{pcn} 111$

Belbin, F. E., Noordally, Z. B., Wetherill, S. J., Atkins, K. A., Franklin, K. A., and Dodd, A. N. (2017). Integration of light and circadian signals that regulate chloroplast transcription by a nuclear-encoded sigma factor. New Phytol. 213, 727-738. doi: 10.1111/nph.14176

Bernal, M., Casero, D., Singh, V., Wilson, G. T., Grande, A., Yang, H., et al. (2012). Transcriptome sequencing identifies SPL7-regulated copper acquisition genes FRO4/FRO5 and the copper dependence of iron homeostasis in Arabidopsis. Plant Cell 24, 738-761. doi: 10.1105/tpc.111.090431

Bueso, E., Alejandro, S., Carbonell, P., Perez-Amador, M. A., Fayos, J., Bellés, J. M., et al. (2007). The lithium tolerance of the Arabidopsis cat2 mutant reveals a cross-talk between oxidative stress and ethylene. Plant J. 52, 1052-1065. doi: 10.1111/j.1365-313X.2007.03305.x

Carmona-Saez, P., Chagoyen, M., Tirado, F., Carazo, J. M., and Pascual-Montano, A. (2007). GENECODIS: a web-based tool for finding significant concurrent annotations in gene lists. Genome Biol. 8, R3. doi: 10.1186/gb-2007-8-1-r3

Carrió-Seguí, A., Garcia-Molina, A., Sanz, A., and Peñarrubia, L. (2015). Defective copper transport in the copt 5 mutant affects cadmium tolerance. Plant Cell Physiol. 56, 442-454. doi: 10.1093/pcp/pcu180

Chen, W. W., Yang, J. L., Qin, C., Jin, C. W., Mo, J. H., Ye, T., et al. (2010). Nitric oxide acts downstream of auxin to trigger root ferric-chelate reductase activity in response to iron deficiency in arabidopsis. Plant Physiol. 154, 810-819. doi: 10.1104/pp.110.161109

Clifton, R., Harvey Millar, A., and Whelan, J. (2006). Alternative oxidases in Arabidopsis: A comparative analysis of differential expression in the gene family provides new insights into function of non-phosphorylating bypasses. Biochim. Biophys. Acta 1757, 730-741. doi: 10.1016/j.bbabio.2006.03.009

Colangelo, E. P., and Guerinot, M. L. (2004). The essential basic helix-loop-helix protein FIT1 is required for the iron deficiency response. Plant Cell 16, 34003412. doi: 10.1105/tpc.104.024315

Connolly, E. L., Fett, J. P., and Guerinot, M. L. (2002). Expression of the IRT1 metal transporter is controlled by metals at the levels of transcript and protein accumulation. Plant Cell 14, 1347-1357. doi: 10.1105/tpc.001263

Crichton, R. R., and Pierre, J. L. (2001). Old iron, young copper: from Mars to Venus. Biometals 14, 99-112. doi: 10.1023/a:1016710810701

Cui, Y., Chen, C. L., Cui, M., Zhou, W. J., Wu, H. L., and Ling, H. (2018). Four IVa bHLH transcription factors are novel interactors of FIT and mediate JA inhibition of iron uptake in Arabidopsis. Mol. Plant 11, 1166-1183. doi: 10.1016/j.molp.2018.06.005

Cuypers, A., Karen, S., Jos, R., Kelly, O., Els, K., Tony, R., et al. (2010). The cellular redox state as a modulator in cadmium and copper responses in Arabidopsis thaliana seedlings. J. Plant Physiol. 168, 309-316. doi: 10.1016/ j.jplph.2010.07.010

da Silva, E. M., Silva, G. F. F. E., Bidoia, D. B., da Silva Azevedo, ,. M., de Jesus, F. A., Pino, L. E., et al. (2017). microRNA159-targeted SlGAMYB transcription factors are required for fruit set in tomato. Plant J. 92, 95-109. doi: 10.1111/tpj.13637

Davison, P. A., Schubert, H. L., Reid, J. D., Iorg, C. D., Heroux, A., Hill, C. P., et al. (2005). Structural and biochemical characterization of Gun4 suggests a mechanism for its role in chlorophyll biosynthesis. Biochemistry 44, 76037612. doi: 10.1021/bi050240x

Di Rienzo, J. A., Casanoves, F., Balzarini, M. G., Gonzalez, L., Tablada, M., and Robledo, C. W. (2011). InfoStat.

Edgar, R. (2002). Gene Expression Omnibus: NCBI gene expression and hybridization array data repository. Nucleic Acids Res. 30, 207-210. doi: $10.1093 /$ nar/30.1.207

Garcia-Molina, A., Andrés-Colás, N., Perea-García, A., Neumann, U., Dodani, S. C., Huijser, P., et al. (2013). The Arabidopsis COPT6 Transport Protein Functions In Copper Distribution Under Copper-Deficient Conditions. Plant Cell Physiol. 0, 113. doi: $10.1093 / \mathrm{pcp} / \mathrm{pct} 088$

Garcia-Molina, A., Altmann, M., Alkofer, A., Epple, P. M., Dangl, J. L., and FalterBraun, P. (2017). LSU network hubs integrate abiotic and biotic stress responses via interaction with the superoxide dismutase FSD2. J. Exp. Bot. 68, 1185-1197. doi: 10.1093/jxb/erw498

Grillet, L., Ouerdane, L., Flis, P., Hoang, M. T. T., Isaure, M. P., Lobinski, R., et al. (2014). Ascorbate efflux as a new strategy for iron reduction and transport in plants. J. Biol. Chem. 289, 2515-2525. doi: 10.1074/jbc.M113.514828

Grillet, L., Lan, P., Li, W., Mokkapati, G., and Schmidt, W. (2018). IRON MAN is a ubiquitous family of peptides that control iron transport in plants. Nat. Plants. 4, 953-963. doi: 10.1038/s41477-018-0266-y

Gulec, S., and Collins, J. F. (2014). Molecular mediators governing iron-copper interactions. Annu. Rev. Nutr. 34, 95-116. doi: 10.1146/annurev-nutr-071812161215

Hindt, M. N., Akmakjian, G. Z., Pivarski, K. L., Punshon, T., Baxter, I., Salt, D. E., et al. (2017). BRUTUS and its paralogs, BTS LIKE1 and BTS LIKE2, encode important negative regulators of the iron deficiency response in Arabidopsis thaliana. Metallomics 9, 876-890. doi: 10.1039/c7mt00152e

Hirayama, T., Lei, G. J., Yamaji, N., Nakagawa, N., and Ma, J. F. (2018). The putative peptide gene FEP1 regulates iron deficiency response in Arabidopsis. Plant Cell Physiol. 59, 1739-1752. doi: 10.1093/pcp/pcyl45

Kastoori Ramamurthy, R., Xiang, Q., Hsieh, E. J., Liu, K., Zhang, C., and Waters, B. M. (2018). New aspects of iron-copper crosstalk uncovered by transcriptomic characterization of Col-0 and the copper uptake mutant: Spl7 in Arabidopsis thaliana. Metallomics 10, 1824-1840. doi: 10.1039/c8mt00287h

Kobayashi, T., Nagasaka, S., Senoura, T., Itai, R. N., Nakanishi, H., and Nishizawa, N. K. (2013). Iron-binding haemerythrin RING ubiquitin ligases regulate plant iron responses and accumulation. Nat. Commun. 4, 2792-2804. doi: 10.1038/ ncomms 3792

Kobayashi, T. (2019). Understanding the complexity of iron sensing and signaling cascades in plants. Plant Cell Physiol. 60, 1440-1446. doi: 10.1093/pcp/pcz038

Kosman, D. J. (2018). The teleos of metallo-reduction and metallo-oxidation in eukaryotic iron and copper trafficking. Metallomics 10, 370-377. doi: 10.1039/ $\mathrm{c} 8 \mathrm{mt} 00015 \mathrm{~h}$

Long, T. A., Tsukagoshi, H., Busch, W., Lahner, B., Salt, D. E., and Benfey, P. N. (2010). The bHLH transcription factor POPEYE regulates response to iron deficiency in arabidopsis roots. Plant Cell 22, 2219-2236. doi: 10.1105/ tpc. 110.074096

Lopez-Millan, A. F., Morales, F., Andaluz, S., Gogorcena, Y., Abadia, A., De Las Rivas, J., et al. (2000). Responses of sugar beet roots to iron deficiency. Changes in carbon assimilation and oxygen use? Plant Physiol. 124, 885-897. doi: 10.1104/ pp.124.2.885

López-Torrejón, G., Jiménez-Vicente, E., Buesa, J. M., Hernandez, J. A., Verma, H. K., and Rubio, L. M. (2016). Expression of a functional oxygen-labile nitrogenase component in the mitochondrial matrix of aerobically grown yeast. Nat. Commun. 7, 1-6. doi: 10.1038/ncomms11426

Macadlo, L. A., Ibrahim, I. M., and Puthiyaveetil, S. (2019). Sigma factor 1 in chloroplast gene transcription and photosynthetic light acclimation. J. Exp. Bot. 71, 1029-1038. doi: 10.1093/jxb/erz464

Marschner, P. (2012). Marschner's Mineral Nutrition of Higher Plants Third Edition (Amsterdam: Elsevier).

Matsumoto, F., Obayashi, T., Sasaki-Sekimoto, Y., Ohta, H., Takamiya, K., and Tatsuru, , M. (2004). Gene expression profiling of the tetrapyrrole metabolic pathway in Arabidopsis with a mini-array system. Plant Physiol. 135, 23792391. doi: 10.1104/pp.104.042408

Mittler, R., Darash-Yahana, M., Sohn, Y. S., Bai, F., Song, L., Cabantchik, I. Z., et al. (2019). NEET Proteins: A new link between iron metabolism, reactive oxygen 
species, and cancer. Antioxid. Redox Signal. 30, 1083-1095. doi: 10.1089/ ars.2018.7502

Moseley, J., Quinn, J., Eriksson, M., and Merchant, S. (2000). The Crd1 gene encodes a putative di-iron enzyme required for photosystem I accumulation in copper deficiency and hypoxia in Chlamydomonas reinhardtii. EMBO J. 19, 2139-2151. doi: 10.1093/emboj/19.10.2139

Murashige, T., and Skoog, F. (1962). A Revised Medium for Rapid Growth and Bio Assays with Tobacco Tissue Cultures. Physiol. Plant 15, 473-497. doi: 10.1111/ j.1399-3054.1962.tb08052.x

Nechushtai, R., Conlan, A. R., Harir, Y., Song, L., Yogev, O., Eisenberg-Domovich, Y., et al. (2012). Characterization of Arabidopsis NEET reveals an ancient role for NEET proteins in iron metabolism. Plant Cell 24, 2139-2154. doi: 10.1105/ tpc.112.097634

Nevitt, T., Öhrvik, H., and Thiele, D. J. (2012). Charting the travels of copper in eukaryotes from yeast to mammals. Biochim. Biophys. Acta 1823, 1580-1593. doi: 10.1016/j.bbamcr.2012.02.011

Nogales-Cadenas, R., Carmona-Saez, P., Vazquez, M., Vicente, C., Yang, X., Tirado, F., et al. (2009). GeneCodis: Interpreting gene lists through enrichment analysis and integration of diverse biological information. Nucleic Acids Res. 37, 317-322. doi: 10.1093/nar/gkp416

Nouet, C., Motte, P., and Hanikenne, M. (2011). Chloroplastic and mitochondrial metal homeostasis. Trends Plant Sci. 16, 395-404. doi: 10.1016/ j.tplants.2011.03.005

Parsons, T., and Strickland, J. (1965). Discussion of spectrophotometric determination of marine-plant pigments, with revised equations for ascertaining chlorophylls and carotenoids. Deep Sea Res. Oceanogr. Abstr. 12, 619. doi: 10.1016/0011-7471(65)90662-5

Peñarrubia, L., Romero, P., Carrió-seguí, A., Andrés-bordería, A., Moreno, J., and Sanz, A. (2015). Plant Traffic and Transport Temporal aspects of copper homeostasis and its crosstalk with hormones. Front. Plant Sci. 6, 255-273. doi: $10.3389 /$ fpls.2015.00255

Perea-García, A., Garcia-Molina, A., Andrés-Colás, N., Vera-Sirera, F., PérezAmador, M. A., Puig, S., et al. (2013). Arabidopsis copper transport protein COPT2 participates in the cross talk between iron deficiency responses and low-phosphate signaling. Plant Physiol. 162, 180-194. doi: 10.1104/ pp.112.212407

Perea-García, A., Andrés-Bordería, A., Mayo de Andrés, S., Sanz, A., Davis, A. M., Davis, S. J., et al. (2016). Modulation of copper deficiency responses by diurnal and circadian rhythms in Arabidopsis thaliana. J. Exp. Bot. 67, 391-403. doi: $10.1093 / \mathrm{jxb} / \mathrm{erv} 474$

Petit, J. M., Briat, J. F., and Lobréaux, S. (2001). Structure and differential expression of the four members of the Arabidopsis thaliana ferritin gene family. Biochem. J. 359, 575-582. doi: 10.1042/0264-6021:3590575

Pfaffl, M. W. (2002). Relative expression software tool (REST(C)) for group-wise comparison and statistical analysis of relative expression results in real-time PCR. Nucleic Acids Res. 30:e36. doi: 10.1093/nar/30.9.e36

Puig, S., Andrés-Colás, N., García-Molina, A., and Peñarrubia, L. (2007). Copper and iron homeostasis in Arabidopsis: Responses to metal deficiencies, interactions and biotechnological applications. Plant Cell Environ. 30, 271290. doi: $10.1111 / j .1365-3040.2007 .01642 . x$

Puig, S. (2014). Function and regulation of the plant COPT family of high-affinity copper transport proteins. Adv. Bot. 2014, 1-9. doi: 10.1155/2014/476917

Rae, T. D., Schmidt, P. J., Pufahl, R. A., Culotta, V. C., and O’Halloran, T. V. (1999). Undetectable intracellular free copper: The requirement of a copper chaperone for superoxide dismutase. Sci. (80-. ). 284, 805-808. doi: 10.1126/ science.284.5415.805

Ravet, K., and Pilon, M. (2013). Copper and iron homeostasis in plants: The challenges of oxidative stress. Antioxid. Redox Signal. 19, 919-932. doi: 10.1089/ars.2012.5084

Ren, F., Logeman, B. L., Zhang, X., Liu, Y., Thiele, D. J., and Yuan, P. (2019). X-ray structures of the high-affi nity copper transporter Ctr1. Nat. Commun. 10, 1386-1395. doi: 10.1038/s41467-019-09376-7

Reyt, G., Boudouf, S., Boucherez, J., Gaymard, F., and Briat, J. F. (2015). Iron- and ferritin-dependent reactive oxygen species distribution: Impact on arabidopsis root system architecture. Mol. Plant 8, 439-453. doi: 10.1016/j.molp.2014.11.014

Robinson, N. J., Procter, C. M., Connolly, E. L., and Guerinot, M. (1999). A ferricchelate reductase for iron uptake from soils. Nature 397, 694-697. doi: 10.1038/ 17800
Rodrigo-Moreno, A., Andrés-Colás, N., Poschenrieder, C., Gunsé, B., Peñarrubia, L., and Shabala, S. (2013). Calcium- and potassium-permeable plasma membrane transporters are activated by copper in Arabidopsis root tips: Linking copper transport with cytosolic hydroxyl radical production. Plant Cell Environ. 36, 844-855. doi: 10.1111/pce.12020

Sancenón, V., Puig, S., Mira, H., Thiele, D. J., and Peñarrubia, L. (2003). Identification of a copper transporter family in Arabidopsis thaliana. Plant Mol. Biol. 51, 577-587. doi: 10.1023/A:1022345507112

Sancenón, V., Puig, S., Mateu-Andrés, I., Dorcey, E., Thiele, D. J., and Peñarrubia, L. (2004). The Arabidopsis Copper Transporter COPT1 Functions in Root Elongation and Pollen Development. J. Biol. Chem. 279, 15348-15355. doi: 10.1074/jbc.M313321200

Sanz, A., Pike, S., Khan, M. A., Carrió-Seguí, À., Mendoza-Cózatl, D. G., Peñarrubia, L., et al. (2019). Copper uptake mechanism of Arabidopsis thaliana high-affinity COPT transporters. Protoplasma 256, 161-170. doi: 10.1007/s00709-018-1286-1

Selinski, J., Scheibe, R., Day, D. A., and Whelan, J. (2018). Alternative Oxidase Is Positive for Plant Performance. Trends Plant Sci. 23, 588-597. doi: 10.1016/ j.tplants.2018.03.012

Selote, D., Samira, R., Matthiadis, A., Gillikin, J. W., and Long, T. A. (2015). Ironbinding E3 ligase mediates iron response in plants by targeting basic helixloop-helix transcription factors. Plant Physiol. 167, 273-286. doi: 10.1104/ pp.114.250837

Stacey, M. G., Patel, A., McClain, W. E., Mathieu, M., Remley, M., Rogers, E. E., et al. (2008). The arabidopsis AtOPT3 protein functions in metal homeostasis and movement of iron to developing seeds. Plant Physiol. 146, 589-601. doi: $10.1104 /$ pp.107.108183

Tanaka, R., and Tanaka, A. (2007). Tetrapyrrole biosynthesis in higher plants. Annu. Rev. Plant Biol. 58, 321-346. doi: 10.1146/annurev.arplant. 57.032905.105448

Tissot, N., Robe, K., Gao, F., Grant-Grant, S., Boucherez, J., Bellegarde, F., et al. (2019). Transcriptional integration of the responses to iron availability in Arabidopsis by the bHLH factor ILR3. New Phytol. 223, 1433-1446. doi: $10.1111 /$ nph. 15753

Tsukagoshi, H., Busch, W., and Benfey, P. N. (2010). Transcriptional regulation of ROS controls transition from proliferation to differentiation in the root. Cell 143, 606-616. doi: 10.1016/j.cell.2010.10.020

Tusher, V., Tibshirani, R., and Chu, G. (2001). Significance analysis of microarrays applied to the ionizing radiation response. Proc. Natl. Acad. Sci. 98, 5116-5121. doi: $10.1073 /$ pnas. 091062498

Varotto, C., Maiwald, D., Pesaresi, P., Jahns, P., Salamini, F., and Leister, D. (2002). The metal ion transporter IRT1 is necessary for iron homeostasis and efficient photosynthesis in Arabidopsis thaliana. Plant J. 31, 589-599. doi: 10.1046/ j.1365-313x.2002.01381.x

Vert, G., Grotz, N., Dédaldéchamp, F., Gaymard, F., Guerinot, L., Briat, J., et al. (2002). IRT1, an Arabidopsis transporter essential for iron uptake from the soil and for plant growth. Plant Cell 14, 1223-1233. doi: 10.1105/tpc.001388

Vigani, G., Maffi, D., and Zocchi, G. (2009). Iron availability affects the function of mitochondria in cucumber roots. New Phytol. 182, 127-136. doi: 10.1111/ j.1469-8137.2008.02747.x

Wang, N., Cui, Y., Liu, Y., Fan, H., Du, J., Huang, Z., et al. (2013). Requirement and functional redundancy of Ib subgroup bHLH proteins for iron deficiency responses and uptake in arabidopsis thaliana. Mol. Plant 6, 503-513. doi: $10.1093 / \mathrm{mp} / \mathrm{sss} 089$

Waters, B. M., and Armbrust, L. C. (2013). Optimal copper supply is required for normal plant iron deficiency responses. Plant Signal. Behav. 8, 1-5. doi: $10.4161 / \mathrm{psb} .26611$

Waters, B. M., McInturf, S. A., and Stein, R. J. (2012). Rosette iron deficiency transcript and microRNA profiling reveals links between copper and iron homeostasis in Arabidopsis thaliana. J. Exp. Bot. 63, 5903-5918. doi: 10.1093/ jxb/ers239

Wofford, J. D., Bolaji, N., Dziuba, N., Wayne Outten, F., and Lindahl, P. A. (2019). Evidence that a respiratory shield in Escherichia coli protects a low-molecularmass FeII pool from O2-dependent oxidation. J. Biol. Chem. 294, 50-62. doi: $10.1074 /$ jbc.RA118.005233

Yamasaki, H., Abdel-Ghany, S. E., Cohu, C. M., Kobayashi, Y., Shikanai, T., and Pilon, M. (2007). Regulation of copper homeostasis by micro-RNA in Arabidopsis. J. Biol. Chem. 282, 16369-16378. doi: 10.1074/jbc.M700138200 
Yamasaki, H., Hayashi, M., Fukazawa, M., Kobayashi, Y., and Shikanai, T. (2009). SQUAMOSA promoter binding protein-like7 is a central regulator for copper homeostasis in Arabidopsis. Plant Cell 21, 347-361. doi: 10.1105/tpc.108.060137

Yruela, I. (2013). Transition metals in plant photosynthesis. Metallomics 5, 10901109. doi: $10.1039 / \mathrm{c} 3 \mathrm{mt} 00086 \mathrm{a}$

Yuan, Y., Wu, H., Wang, N., Li, J., Zhao, W., Du, J., et al. (2008). FIT interacts with AtbHLH38 and AtbHLH39 in regulating iron uptake gene expression for iron homeostasis in Arabidopsis. Cell Res. 18, 385-397. doi: 10.1038/cr.2008.26

Zhang, H., and Krämer, U. (2018). Differential diel translation of transcripts with roles in the transfer and utilization of iron-sulfur clusters in arabidopsis. Front. Plant Sci. 871:1641. doi: 10.3389/fpls.2018.01641
Conflict of Interest: The authors declare that the research was conducted in the absence of any commercial or financial relationships that could be construed as a potential conflict of interest.

Copyright $\odot 2020$ Perea-García, Andrés-Bordería, Vera-Sirera, Pérez-Amador, Puig and Peñarrubia. This is an open-access article distributed under the terms of the Creative Commons Attribution License (CC BY). The use, distribution or reproduction in other forums is permitted, provided the original author(s) and the copyright owner(s) are credited and that the original publication in this journal is cited, in accordance with accepted academic practice. No use, distribution or reproduction is permitted which does not comply with these terms. 